\title{
LA ADMISIÓN TÁCITA DE LOS HECHOS \\ POR NO CONTESTACIÓN DE LA DEMANDA EN EL PROCESO LABORAL
}

\section{THE TACIT ADMISSION OF FACTS DUE TO LACK OF RESPONSE OF THE CLAIM IN THE LABOR PROCESS}

Raúl Fernández Toledo*

\section{Resumen}

En el presente trabajo se analiza el ámbito de aplicación de la admisión tácita de los hechos afirmados en la demanda como consecuencia de su no contestación en el proceso laboral, sus requisitos de procedencia, las consecuencias que derivan de la misma, su naturaleza jurídica y el control de su correcto ejercicio por el juez a través del recurso de nulidad. Para ello se examina su regulación legal -especialmente el art. $453 \mathrm{~N}^{\circ} 1$ inc. $7^{\circ}$ del Código del Trabajo- sobre la base de la jurisprudencia y de la doctrina nacional, además, de utilizar la doctrina extranjera como argumento de refuerzo.

Palabras claves: Admisión tácita, proceso laboral, thema probandum, regla de prueba, relevo de prueba.

\section{AbStRact}

In this paper it is analyzed, regarding the tacit admission of the facts asserted in the lawsuit, as a result of not filing a defense in the labor process, its

* Abogado. Licenciado en Ciencias Jurídicas y Sociales por la Universidad de Concepción. Magíster en Derecho del Trabajo y Seguridad Social (impartido en conjunto por la Universidad de Talca y la Universidad de Valencia). Académico de Derecho del Trabajo y Seguridad Social, Facultad de Derecho de la Universidad de Chile. Dirección postal: Facultad de Derecho, Universidad de Chile, avenida Santa María $\mathrm{N}^{\circ}$ 636, Providencia, Chile. Correo electrónico rfernandez@derecho.uchile.cl. Artículo recibido el 17 de noviembre de 2016 y aceptado para su publicación el 27 de marzo de 2017. Agradezco los valiosos comentarios formulados por los profesores Claudio Palavecino, Rodolfo Caballero y Andrés Dighero, que me permitieron enriquecer el presente artículo. 
scope of application, its requirements to proceed, the legal consequences that derive from it, its legal nature and the judges control of its proper application through the action for annulment. For this purpose, its legal regulation is analyzed -especially article $453 \mathrm{~N}^{\circ} 1$, paragraph 7 of the Labor Code- based on national jurisprudence and doctrine, and additionally, foreign doctrine used as argumentative reinforcement.

Key Words: tacit admission, labor process, thema probandum, canon of evidence, relief of evidence.

\section{INTRODUCCIÓN}

El Código del Trabajo, en el art. $453 \mathrm{~N}^{\circ} 1$ inc. $7^{\circ}$, regula la admisión tácita de los hechos contenidos en la demanda en los siguientes términos:

"En la audiencia preparatoria se aplicarán las siguientes reglas: $1^{\circ}[\ldots]$ Cuando el demandado no contestare la demanda, o de hacerlo no negare en ella algunos de los hechos contenidos en la demanda, el juez, en la sentencia definitiva, podrá estimarlos como tácitamente admitidos".

Se trata de una norma de rango legal que establece el efecto jurídico que puede producir tanto la no contestación como la contestación de la demanda en que no se controvierten todos o algunos de los hechos afirmados por el actor, siendo este efecto la admisión tácita de los hechos contenidos en la demanda no controvertidos en la contestación. La que será total cuando no existiese contestación o, existiendo, no se controvierte ninguno de sus hechos por parte de los demandados, debido a que en tales supuestos no se niega ningún hecho afirmado.

La norma transcrita es una de las que regula el procedimiento de aplicación general. Debido a que la normativa del mismo tiene aplicación supletoria en los procesos de tutela laboral y monitorio (art. 432 del Código del Trabajo $)^{1}$, el inc. $7^{\circ}$ del $\mathrm{N}^{\circ} 1$ del art. 453 se aplica también a estos últimos, al no existir ninguna disposición similar en su regulación que

${ }^{1} \mathrm{El}$ art. 432 del Código del Trabajo señala: "En todo lo no regulado en este Código o en leyes especiales, serán aplicables supletoriamente las normas contenidas en los Libros I y II del Código de Procedimiento Civil, a menos que ellas sean contrarias a los principios que informan este procedimiento. En tal caso, el tribunal dispondrá la forma en que se practicará la actuación respectiva.

No obstante, respecto de los procedimientos especiales establecidos en los Párrafos $6^{\circ}$ y $7^{\circ}$ de este Capítulo II, se aplicarán supletoriamente, en primer lugar, las normas del procedimiento de aplicación general contenidas en su Párrafo 3 \%”. 
establezca las consecuencias jurídicas que derivan de la no contestación de la demanda y de la falta de controversia en la contestación de los hechos afirmados por el actor.

Del mismo modo, se aplica también al procedimiento conforme al cual se tramitan la reclamación de multas y demás resoluciones administrativas laborales a aquel en que se reglamentan las denuncias de prácticas antisindicales y desleales, toda vez que la normativa que regula estas materias se remite a los procesos donde tiene aplicación el art. $453 \mathrm{~N}^{\circ} 1$ inc. $7^{\circ} \mathrm{del}$ Código del Trabajo. De esta forma, la admisión tácita rige en todos los procedimientos judiciales laborales, no existiendo discusión al respecto.

En lo que existe controversia es en la admisión tácita por falta de contestación de la demanda, existiendo varias preguntas por responder en cuanto a sus requisitos de procedencia y en lo tocante a sus consecuencias jurídicas -no obstante la aparente claridad del art. $453 \mathrm{~N}^{\circ} 1$ inc. $7^{\circ} \mathrm{del}$ Código del Trabajo-, existen distintas interpretaciones sobre su sentido y alcance en la doctrina ${ }^{2}$ y jurisprudencia nacional. Situación que tiene una influencia decisiva en la determinación de los requisitos y efectos de la admisión tácita por no contestación.

De esta forma, no existe claridad si basta únicamente con que no exista contestación oportuna para que el juez pueda tener por tácitamente admitidos los hechos contenidos en la demanda o si, por el contrario, es necesario, además, que el demandado no comparezca a la audiencia preparatoria (o única, tratándose del procedimiento monitorio). Asimismo, existen dudas si procede esta admisión tácita cuando los demandados son varios y algunos contestaron la demanda y otros no.

Tampoco es pacífica la oportunidad en que puede ejercerse por el juez la admisión tácita por falta de contestación; si antes de la fijación de los hechos sustanciales, pertinentes y controvertidos, operando como un supuesto en que estos no existen o, bien, en la sentencia definitiva dictada luego de concluido totalmente el procedimiento regulado por el Código del Trabajo. Divergencia que se ha suscitado al señalar el art. $453 \mathrm{~N}^{\circ} 1$ inc. $7^{\circ}$ que la admisión tácita podrá hacerla efectiva el juez "en la sentencia definitiva". Lo anterior, por cuanto es discutido en la doctrina y en la jurisprudencia judicial nacional si el juez en virtud de esta norma puede dictar una sentencia definitiva durante la etapa de discusión del procedimiento sin necesidad de entrar a la etapa de prueba por no existir

${ }^{2}$ Los trabajos que han tratado algún aspecto de la admisión tácita de los hechos por no contestación de la demanda en el proceso laboral nacional son: SiLVA (2009), pp. 65-71; Carrasco (2010), pp. 119-148; Palavecino (2010a), pp. 6-8; Aránguiz (2011), pp. 86-99; Fernández (2011a), pp. 228-235; DíAz (2012), pp. 74-80; Zepeda (2013), pp. 199-218; Delgado (2014), pp. 497-522. 
hechos controvertidos como consecuencia de la admisión tácita o, por el contrario, necesariamente debe hacerlo en la oportunidad prevista por los arts. 457 y 500 del Código del Trabajo; esto es, en la sentencia definitiva dictada luego de concluida la audiencia en que se rindió la prueba. Por lo demás, esta discusión tiene incidencia directa en el contenido de la sentencia definitiva, la cual es distinta según la oportunidad en que pueda ejercerse la admisión tácita por no contestación.

Estrechamente vinculado con el problema anterior se encuentra el de la determinación de la naturaleza jurídica de la admisión táctica por no contestación de la demanda, discutiéndose si es un supuesto de exención de prueba, por permitir al juez no recibir la causa a prueba o, bien, es una regla legal de naturaleza probatoria que puede utilizar el juez para establecer como verdaderos los hechos sustanciales, pertinentes y controvertidos que son de carga del demandante. Determinación que es relevante, puesto que permite establecer los efectos jurídicos de la admisión táctica por no contestación y los alcances de la misma.

Asimismo, es importante establecer si esta admisión táctica es una sanción procesal para el demandado rebelde o simplemente la consecuencia del no cumplimiento de una carga procesal de este, como también precisar el alcance facultativo que tiene para el juez la admisión tácita.

94 En consecuencia, no existe claridad sobre los requisitos de procedencia de la admisión tácita de los hechos afirmados en la demanda por no contestación de la misma. Tampoco es pacífica su naturaleza jurídica y efectos, siendo importante dilucidar estas cuestiones, desde que permitirán al juez obrar ajustado a Derecho, como lo ordena la Constitución Política (arts. 6 y 7) y, a las partes ejercer sus derechos procesales debidamente. De ahí que en el presente trabajo se dé respuesta a los problemas planteados, la que puede ayudar a la correcta regulación de los efectos de la rebeldía del demandado en la futura Reforma Procesal Civil ${ }^{3}$. Siendo, por tanto, el objetivo es analizar críticamente la admisión tácita por no contestación de la demanda en el proceso laboral nacional ${ }^{4}$.

En razón de lo anterior se realiza la siguiente exposición:

i) requisitos para la procedencia de la admisión tácita por falta de contestación de la demanda;

${ }^{3}$ Véase sobre el tratamiento de la rebeldía del demandado en el proceso civil nacional y comparado: Orellana y Pérez (2007), pp. 13-44. Sobre el tratamiento de la rebeldía del en el proceso civil vigente en Chile y en el Proyecto de Reforma del Proceso Civil véase: Carrasco (2009), pp. 155-209; Carrasco (2010), pp. 23-118; Delgado (2014), pp. 497-522.

${ }^{4}$ En el presente trabajo no se analizan los otros supuestos de admisión tácita regulados en el art. $453 \mathrm{~N}^{\circ} 1$ inc. $7^{\circ}$ del Código del Trabajo. Es así que, no se trata la admisión tácita que tiene lugar cuando el demandado contesta y no niega en ella todos o algunos de los hechos contenidos en ella. 
ii) naturaleza jurídica y efectos de la admisión tácita que se analiza;

iii) requisitos de la sentencia en que se hace efectiva la admisión tácita por falta de contestación de la demanda;

iv) control de la aplicación de la admisión tácita a través del recurso de nulidad y

v) reflexiones finales ${ }^{5}$.

Para lograr los objetivos propuestos, se recurrió a fuentes normativas y bibliográficas ${ }^{6}$. Se utilizó igualmente la jurisprudencia judicial nacional ${ }^{7}$, que, si bien no es fuente formal del Derecho en nuestro ordenamiento jurídico tiene una trascendencia fundamental en la construcción dogmática de la admisión tácita en el proceso laboral nacional. Específicamente, se examinaron pronunciamientos particulares realizados por los tribunales de justicia en juicios donde se discutió la procedencia de la admisión tácita por falta de contestación de la demanda, todo lo cual contribuyó a dar respuesta a los problemas jurídicos planteados.

\section{REQUiSITOS DE LA ADMISIÓN TÁCITA POR NO CONTESTACIÓN}

DE LA DEMANDA

Es del caso señalar que antes del año 2009 no existía en el legislación laboral nacional norma que regulase los efectos de la falta de contestación en el proceso laboral, por lo que operaba plenamente el régimen de la contestación ficta de la demanda, regulado en el Código de Procedimiento Civil en el evento de que el demandado no contestara, debiendo, por tanto, el juez recibir la causa a prueba, fijando los hechos sustanciales, pertinentes y controvertidos, siendo carga del demandante acreditar los hechos afirmados en el libelo, por constituir la causa de pedir de sus pretensiones ${ }^{8}$.

${ }^{5}$ Toda referencia en este trabajo a la admisión táctica sin ninguna otra agregación se entiende referida a la admisión tácita por no contestación de la demanda.

${ }^{6}$ Especialmente se recurrió a las investigaciones que los autores nacionales han realizado sobre la admisión tácita de los hechos, sea en monografías, obras de derecho colectivo, como también en artículos publicados en revistas especializadas. Por su parte, la doctrina extranjera se utilizó como argumento de refuerzo en forma recurrente.

${ }^{7}$ Se ha considerado como universo de estudio las sentencias de los tribunales superiores de justicia, es decir, de las cortes de apelaciones del país y de la Corte Suprema, que han sido dictadas entre los años 2008 a 2016, cuyo conocimiento se ha adquirido a través de la página web del Poder Judicial, debido a la revisión que de los estados diarios de esos tribunales efectuada por parte del autor durante el periodo señalado.

${ }^{8}$ Sobre la contestación ficta de la demanda que regía en el proceso laboral anterior al que rige actualmente se ha señalado: "En el procedimiento laboral anterior a la reforma establecida por las leyes $\mathrm{N}^{\circ} 20.087$ y $\mathrm{N}^{\circ} 20.226$, la regla general era la contraria, es decir, 
No fue sino hasta la dictación de la ley $\mathrm{N}^{\circ} 20.087$-que reemplazó en forma íntegra el proceso laboral anterior- que se introdujo la posibilidad de tener por tácitamente admitidos los hechos afirmados por el demandante en caso que el demandado no contestase, estableciéndose tal figura originalmente en el art. $453 \mathrm{~N}^{\circ} 1$ inc. $3^{\circ}$ del Código del Trabajo 9 .

Debido a ciertos ajustes realizados al proceso laboral instaurado por la ley $\mathrm{N}^{\circ} 20.087$ a través de la ley $\mathrm{N}^{\circ} 20.226$, quedó definitivamente regulada la admisión tácita en el actual art. $453 \mathrm{~N}^{\circ} 1$ inc. $7^{\circ}$ del Código del Trabajo. Norma a la que -según se señaló- se le han atribuido diversos alcances $\mathrm{y}$ efectos por la doctrina y jurisprudencia nacional, muchas veces contradictorios.

Ahora bien, lo primero que corresponde establecer son los requisitos que deben cumplirse para que el juez pueda tener por tácitamente admitidos los hechos afirmados en la demanda como consecuencia de su falta de contestación. Aspecto muy relevante, puesto que la sola concurrencia de los supuestos fácticos que establece la norma legal permitirá al juez ejercer la admisión tácita, objeto del presente trabajo.

\section{Demanda, citación y notificación válida}

96 El primer requisito está constituido por la interposición de una demanda ante un tribunal competente, esto es, ante un juzgado de letras del trabajo o juzgado civil con competencia laboral, que se admita a tramitación por el juez, se cite a las partes a la audiencia correspondiente y que se realice la notificación en forma válida de la demanda y de la resolución recaída sobre ella dentro de plazo ${ }^{10}$; se requiere que el demandado sea debidamente emplazado. Solo cumpliéndose estas condiciones estará en condiciones de contestar la demanda, naciendo su carga procesal en este sentido.

si el demandado no contestaba la demanda entonces se entendía que negaba todos los hechos afirmados por el actor en su demanda, es decir, el actor, para poder obtener una sentencia definitiva estimatoria debía probar los hechos constitutivos de su pretensión, los cuales se entendían controvertidos por la actitud rebelde del demandado. En definitiva, se aplicaba aquel proverbio qui tacet non consentire videtur; es decir, quien calla no otorga". Carrasco (2010), p. 122.

${ }^{9}$ Señalaba el art. $453 \mathrm{~N}^{\circ} 1$ inc. $3^{\circ}$ del Código del Trabajo introducido por la ley $\mathrm{N}^{\circ} 20.087$ : "En la audiencia preparatoria se aplicarán las siguientes reglas: 1) [...] Cuando el demandado no concurriere a la audiencia preparatoria, o de hacerlo no negare en su contestación algunos de los hechos contenidos en la demanda, el juez, en la sentencia definitiva, podrá estimarlos como tácitamente admitidos". Historia de la Ley $\mathrm{N}^{\circ} 20.087$, p. 892, disponible en www.leychile.cl/Consulta/portada_hl?tipo_norma=XX1\&nro_ley=20087 [Fecha de consulta: 2 de agosto de 2016].

${ }^{10}$ Véase un mayor tratamiento de esta exigencia: CARRASCO (2010), pp. 23-29. 
Si bien este requisito no está señalado en el art. $453 \mathrm{~N}^{\circ} 1$ inc. $7^{\circ}$ del Código del Trabajo, lo cierto es que emana de los arts. $451^{11}$ y $436^{12}$ del mismo Código, siendo esencial para la formación de la relación procesal el que la notificación se haga en forma válida y dentro de plazo ${ }^{13}$.

De no concurrir los requisitos indicados, evidentemente no nace para el demandado la carga procesal de contestar, por faltar, precisamente, el presupuesto para el nacimiento de la demanda, lo que ocasionaría la imposibilidad de aplicar la consecuencia en comento, esto es, el admitirse tácitamente los hechos afirmados en ella ${ }^{14}$.

Por su parte, la demanda debe cumplir necesariamente con la exigencia establecida en el art. $446 \mathrm{~N}^{\circ} 4$ del Código del Trabajo, el cual señala:

"la demanda se interpondrá por escrito y deberá contener: [...] 4. La exposición clara y circunstanciada de los hechos [...] en que se fundamenta".

Mismo requisito que debe cumplir la demanda reconvencional (art. 452 inc. final del Código del Trabajo). Ello porque si no cumple con esta exigencia no existen hechos que puedan ser admitidos tácitamente por el juez. Es presupuesto esencial de la admisión tácita por no contestación que el libelo contenga una exposición clara y circunstanciada de los hechos que constituyen la causa de pedir de las pretensiones del demandante, debiendo cumplir con la carga impuesta por el art. 446 del Código del

${ }^{11}$ Señala el art. 451 del Código del Trabajo: "Admitida la demanda a tramitación, el tribunal deberá, de inmediato y sin más trámite, citar a las partes a una audiencia preparatoria, fijando para tal efecto, dentro de los treinta y cinco días siguientes a la fecha de la resolución, el día y la hora para su celebración, debiendo mediar entre la notificación de la demanda y citación, y la celebración de la audiencia, a lo menos, quince días.

En la citación se hará constar que la audiencia preparatoria se celebrará con las partes que asistan, afectándole a aquella que no concurra todas las resoluciones que se dicten en ella, sin necesidad de ulterior notificación. Asimismo, deberá indicarse en la citación que las partes, en dicha audiencia, deberán señalar al tribunal todos los medios de prueba que pretendan hacer valer en la audiencia oral de juicio, como así también requerir las diligencias de prueba atinentes a sus alegaciones, para que el tribunal examine su admisibilidad".

${ }^{12}$ Establece el art. 436 inc. $1^{\circ}$ del Código del Trabajo: "La primera notificación a la parte demandada deberá hacerse personalmente, entregándosele copia íntegra de la resolución y de la solicitud en que haya recaído. Al demandante se le notificará por el estado diario". Precepto que se complementa con los arts. 437, 438, 439 y 439 bis del Código del Trabajo, que regulan otras formas de notificación de la demanda cuando la notificación personal no fuere posible.

${ }^{13}$ Carrasco (2010), p. 24; Sindicato de Tripulantes de CPT Remolcadores S.A. con CPT Remolcadores S.A. (2016).

${ }^{14}$ Páez con Exportadora e Importadora Turken S.A. (2016). 
Trabajo $^{15}$. El juez no puede subsanar los defectos en cuanto a los hechos, agregando nuevos o complementando los indicados, por impedirlo el principio dispositivo imperante en el proceso laboral ${ }^{16}$. Por lo que si la demanda no contiene una exposición clara y circunstanciada de los hechos, estos no se pueden admitir tácitamente, aun cuando concurran los demás requisitos de procedencia.

\section{No contestación de la demanda}

No se discute que una de las hipótesis de procedencia de la admisión tácita tiene lugar "cuando el demandado no contestare la demanda", tal como lo señala el art. $453 \mathrm{~N}^{\circ} 1$ inc. $7^{\circ}$, por tanto, es necesario que el demandado no conteste. Se trata de un requisito esencial para la procedencia de la admisión tácita por no contestación. De ahí que sea de importancia determinar cuándo no existe contestación de demanda.

Tratándose del procedimiento de aplicación general, el art. 452 del Código del Trabajo establece que el demandado debe contestar por escrito dentro de los cinco días hábiles anteriores a la audiencia preparatoria. Norma que es aplicable a todos los procedimientos que se tramitan conforme a aquel de aplicación general. El plazo indicado es de carácter fatal, tal como lo establece el art. 435 del Código del Trabajo, extinguiéndose por el solo transcurso del tiempo.

Por su parte, la demanda reconvencional debe ser contestada en la audiencia preparatoria y de forma oral (art. $453 \mathrm{~N}^{\circ} 1$ inc. $3^{\circ}$ del Código del Trabajo).

En el procedimiento monitorio el demandado debe contestar verbalmente en la audiencia única de conciliación, contestación y prueba (art. 499 del Código del Trabajo).

2.a) No contestación de la demanda y contestación extemporánea de la demanda

Teniendo presente la regulación que hace el Código del Trabajo de la contestación, resulta claro que no existe cuando el demandado no la presenta ante el tribunal que está conociendo del procedimiento tramitado en con-

${ }^{15}$ Concha con Salazar (2015).

${ }^{16}$ Fernández (2011b), p. 42; Montero con Ingeproc Ltda. (2013), sentencia que señala: "Cuarto: [...] Al respecto antes de analizar las probanzas se debe consignar que el impulso oficioso del Juez del Trabajo tiene limitaciones, así no alcanza para levantar hechos no indicados por las partes en sus escritos principales. En efecto la órbita de competencia del Tribunal queda limitada a los hechos que presentan las partes, la labor del juez consiste en tal sentido en intentar la acreditación o desestimación de los mismos"; CruCEs (2015), pp. 208-221. En sentido contrario: PALAVEcino (2011a), pp. 124-127. 
formidad con las reglas de aplicación general con a lo menos cinco días hábiles de anticipación a la audiencia preparatoria, ni lo hace tampoco con posterioridad a esa oportunidad, ni antes ni después de la audiencia preparatoria. Lo mismo ocurre cuando no se contesta la demanda reconvencional al momento de evacuar el traslado que le confiere el tribunal ni cuando se da traslado de la demanda interpuesta en procedimiento monitorio en la oportunidad prevista en la ley.

Las dudas surgen cuando el demandado contesta extemporáneamente, esto es, con posterioridad a la oportunidad establecida en el Código del Trabajo. La pregunta que origina esta situación es si la contestación extemporánea constituye o no contestación de la demanda desde el punto de vista procesal. La respuesta no es intrascendente, desde que la misma permitirá o no al juez de la instancia tener por tácitamente admitidos los hechos afirmados en la demanda.

No existe una respuesta unánime para esta pregunta, llegando, incluso, a encontrarse soluciones contradictorias en la jurisprudencia judicial nacional que se ha pronunciado al respecto.

En efecto, una corriente jurisprudencial sostiene que, si bien materialmente es distinta la contestación extemporánea de la demanda, de la falta contestación de la misma, desde un punto de vista procesal ambas situaciones son idénticas, por tanto, procesalmente la contestación extemporánea de la demanda no constituye contestación, no existiendo la misma en el proceso ${ }^{17}$.

Dicha posición encuentra sustento en que los plazos establecidos por el Código del Trabajo para el proceso laboral son de carácter fatal (art. 435 del Código del Trabajo), por lo que si transcurrió la oportunidad procesal para contestar se extingue de pleno derecho tal posibilidad, no alterándose por una extemporánea, la que, de tener lugar, no debe ser admitida por el juez por presentarse fuera de plazo. Se trata del efecto normal de la preclusión ${ }^{18}$, la que tiene lugar cuando transcurre el plazo para contestar la demanda sin hacerlo.

Otro sector de la doctrina judicial sostiene que en la contestación extemporánea de la demanda efectuada antes de la audiencia en que se debe ofrecer prueba existe contestación, aun cuando se haya efectuado extemporáneamente. La misma tiene suficiente mérito para controvertir los hechos afirmados por el demandante, debiendo, por consiguiente, recibirse la

${ }^{17}$ Lagos con Cortez y otro (2013); Compañía Minera Doña Inés de Collahuasi SCM con Inspección Provincial del Trabajo de Iquique (2013); Mamani con Ilustre Municipalidad de Camiña (2013); Contreras con Monras y Gunther Ltda. (2014); González con Sociedad Agro Ganadera Forestal y Frutícola Buena Vista Ltda. (2014); Bustamante con Fernández (2016).

${ }^{18}$ Colombo (1997), pp. 509-516. 
causa a prueba, fijándose los hechos sustanciales pertinentes y controvertidos, no pudiendo el juez ejercer la facultad del art. $453 \mathrm{~N}^{\circ} 1$ inc. $7^{\circ}$ del Código del Trabajo ${ }^{19}$. Se agrega que la no contestación y la contestación de la demanda fuera de plazo son situaciones jurídicas distintas, por lo que no resulta procedente aplicar a esta última situación el efecto previsto en el art. $453 \mathrm{~N}^{\circ} 1^{\circ}$ inc. $7^{\circ}$ del Código del Trabajo, debido a que este inciso no tiene como supuesto fáctico para su aplicación la contestación fuera de plazo, sino únicamente la no contestación. Esta posición termina concluyendo que, atendido el efecto perjudicial que tiene la admisión tácita para el demandado rebelde, debe ser aplicada restrictivamente ${ }^{20}$.

A nuestro entender, debido a que los plazos establecidos en el Libro V del Código del Trabajo son fatales (art. 435 del Código del Trabajo), los actos procesales que no se realizan en la oportunidad prevista por el Código no pueden efectuarse válidamente con posterioridad por haber precluido la oportunidad que se tenía para ello. De ahí que la contestación de demanda extemporánea no constituye contestación, no existiendo en el proceso. Tal efecto es simplemente expresión de la preclusión por vencimiento del plazo $^{21}$. Sostener lo contrario importaría pasar por alto la norma contenida en el art. 435 del Código del Trabajo, desconociéndose que los plazos del libro v del Código del Trabajo son fatales. Además, si se tratara de forma igual las contestaciones de demanda dentro de plazo y extemporánea, se corre el riesgo de afectar el derecho a defensa del demandante, porque conlleva a que este no conozca oportunamente la contestación y la teoría del caso de su contraparte, no teniendo tiempo suficiente para defenderse de la misma ${ }^{22}$. En especial, en las controversias tramitadas conforme al procedimiento de aplicación general, una contestación extemporánea puede provocar un desconocimiento de las posibles probanzas de que se valdrá el demandado, toda vez que el plazo de los cinco días hábiles anteriores a la celebración de la audiencia preparatoria otorgados para la contestación tiene por objetivo permitir al demandante tener un conocimiento previo tanto de la línea argumentativa como de la teoría del caso del demandado, y con ello de las posibles probanzas de que se valdrá en juicio ${ }^{23}$; plazo que no tendrá con una contestación extemporánea.

${ }^{19}$ Fuentes con Francisco Gómez e Hijo Ltda. (2010); Águila con Invertec Pesquera Mar de Chiloé S.A. (2010); Hernández con Sociedad Agrícola Alborada S.A. (2014); Orellana con Constructora Antártida Ltda. y otra (2015).

${ }^{20}$ Fuentes con Francisco Gómez e Hijo Ltda. (2010); Águila con Invertec Pesquera Mar de Chiloé S.A. (2010); Ramos con Sepúlveda (2014).

${ }^{21}$ Cоlombo (1997), p. 519.

${ }^{22}$ DíAz (2012), p. 75.

${ }^{23}$ Ibid. 
2.b) No contestación de la demanda

en el litisconsorcio pasivo

La admisión tácita por no contestación se aplica a toda parte demandada, incluso, en el supuesto de litisconsorcio pasivo, voluntario o necesario. Al no distinguir el art. $453 \mathrm{~N}^{\circ} 1$ inc. $7^{\circ}$ del Código del Trabajo, no corresponde distinguir ni excluir de su aplicación a algunos demandados. Sin embargo, en el caso del litisconsorcio pasivo surge el problema de determinar si la falta de contestación por uno de los litisconsortes vincula al otro que contestó en tiempo y forma o, por el contrario, la contestación de uno de los litisconsortes puede extenderse al que no ha contestado o, bien, la posición procesal de los litisconsortes tiene un carácter autónomo para los efectos de la no contestación de la demanda.

Para resolver el problema planteado corresponde distinguir entre litisconsorcio pasivo necesario ${ }^{24}$ y litisconsorcio pasivo facultativo ${ }^{25}$.

En el litisconsorcio pasivo necesario ${ }^{26}$ la unidad de pretensiones y causas de pedir respecto de todos los demandados excluye la tercera solución;

${ }^{24}$ El ejemplo más evidente de litisconsorcio pasivo necesario se encuentra en la acción declarativa de empleador común regulada en el art. 3 inc. $4^{\circ}$ del Código del Trabajo y, en sus acciones accesorias de simulación y subterfugio reguladas en el art. 507 del Código del Trabajo, toda vez, que debe demandarse necesariamente al menos a dos empleadores que se encuadran en el supuesto de empleador común para que dichas acciones puedan prosperar.

${ }^{25}$ El litisconsorcio pasivo facultativo tiene lugar en la subcontratación, desde que el trabajador puede demandar a su empleador y, además, si lo estima pertinente, a la empresa principal que le prestó servicios en régimen de subcontratación por las obligaciones laborales y previsionales de dar que se le adeuden por su empleador (art. 183-B del Código del Trabajo). Es facultad del trabajador demandante accionar o no en contra de la empresa principal, y lo hace fundado en una causa de pedir distinta a la pretensión dirigida contra el empleador, cual es el trabajo en régimen de subcontratación. Véase un mayor tratamiento de este tipo de litisconsorcio en Palavecino (2010b), pp. 17-27; Palavecino (2011b), pp. 263-267.

También tiene cabida el litisconsorcio pasivo facultativo en la responsabilidad civil por accidentes del trabajo y enfermedades profesionales cuando el empleador y la empresa principal incumplen su correspondiente obligación de seguridad, desde que el trabajador afectado puede demandar a ambos en un mismo o diferente proceso o, bien, demandar a uno solo de ellos. La causa de pedir de la acción del trabajador respecto del empleador lo constituye el art. 184 del Código del Trabajo y su normativa complementaria, y respecto de la empresa principal el art. 183-E del mismo Código junto a su normativa complementaria. Véase entre otros DiEz (2008), pp. 171-177; BARRIENTOS (2012), pp. 82-87.

${ }^{26}$ El litisconsorcio pasivo necesario exige la intervención en el proceso, desde su iniciación, de todos litisconsortes pasivos. Existe solamente cuando la demanda, para interponerse válidamente, debe dirigirse contra todos lo litisconsortes pasivos. Cfr. CARRASCO (2010), pp. 71-72. Las características esenciales del litis consorcio necesario son: "a) los actos de disposición del objeto del proceso (desistimiento, allanamiento, transacción) sólo producen efectos cuando concurren todos los litisconsortes necesarios; b) se debe pronunciar una sentencia única para todos los sujetos que necesariamente deben ser partes de la relación procesal y; c) las defensas o excepciones favorecen a todos los litisconsortes necesarios”. ROMERO (1998), p. 393. 
no tiene cabida la posibilidad de limitar los efectos de la contestación o no contestación a solo alguno de los litisconsortes pasivos ${ }^{27}$. Por tanto, corresponde determinar si se extiende rebelde la contestación de la demanda efectuada por otro o, bien, prevalece la no contestación respecto de todos los litisconsortes pasivos necesarios, rebeldes y no rebeldes.

Tiene importancia para estos efectos conocer el fundamento de la admisión tácita por no contestación de la demanda. Si el mismo reside en el principio dispositivo sustancial -como lo sostiene la doctrina ${ }^{28}-\mathrm{y}$ en establecer efectos perjudiciales para el litigante negligente, extender la eficacia de la no contestación de uno de los litisconsortes a los que sí han contestado en tiempo y forma, importa una indebida extensión de la voluntad de aquel que no contesta al que sí ha contestado ${ }^{29}$. Pero también se ha hecho notar que la solución opuesta -aquella según la cual la contestación por una parte es suficiente para no tener cabida la admisión tácita- produce el inconveniente de extender los efectos de la voluntad de la parte que contestó a aquella que no contestó, a la que no manifestó su voluntad expresamente respecto de los hechos afirmados en la demanda ${ }^{30}$.

No obstante, los inconvenientes expresados, si se parte de la premisa según la cual la admisión tácita por no contestación es reconducible al principio dispositivo sustancial, la solución que presenta menores inconvenientes es aquella que sostiene como idónea la contestación de un litisconsorte pasivo necesario para que los hechos afirmados por el demandante sean acreditados en el proceso, debiendo, por tanto, recibirse la causa a prueba. Además, no resulta posible extender los efectos de la no contestación a una parte que sí lo hizo ${ }^{31}$, no concurriendo en este supuesto el hecho esencial que exige el art. $453 \mathrm{~N}^{\circ} 1$ inc. $3^{\circ}$ del Código del Trabajo: no contestación de la demanda.

Esta respuesta es, además, coherente con la institución misma del litisconsorcio necesario, puesto que, al tratarse de una relación procesal única, la resolución judicial que se dicte será igual para todos los litisconsortes pasivos necesarios, produciendo los mismos efectos en todos ellos. Consecuencia que conlleva a que los actos jurídicos procesales realizados por cualquier litisconsorte producen efectos respecto de los demás ${ }^{32}$. Es por ello que no se produce el efecto de la no contestación si uno de los litisconsortes pasivos necesarios contesta, aunque los otros no lo hagan, permaneciendo aquellos en rebeldía, desde que la contestación realiza-

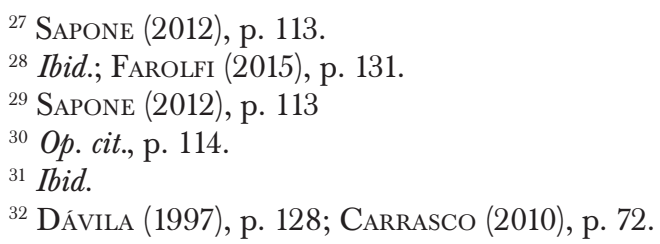


da por uno produce efectos respecto de todos los litisconsortes pasivos necesarios.

Tratándose del litisconsorcio pasivo facultativo, si bien hay unidad formal del proceso, las pretensiones que se reclaman de los demandados conservan autonomía. Tanto es así que el demandante pudo no demandar a alguno de los litisconsortes y conservar la eficacia de las pretensiones reclamadas respecto del que sí fue demandado. La cuestión consiste en establecer si la unidad del proceso o autonomía de las pretensiones influye sobre la facultad del juez y sobre la situación de las partes demandadas producto de la no contestación de uno de los litisconsortes pasivos.

La respuesta que tradicionalmente se ha dado en la doctrina es que al ser cada sujeto independiente de los demás en el proceso, la actividad o inactividad de cada uno de los litisconsortes no afecta ni altera la situación procesal de los otros, desde que en todo litisconsorcio facultativo el resultado del proceso y el contenido de la sentencia pueden ser diferentes con respecto a cada uno de ellos ${ }^{33}$.

De este modo, si uno o más litisconsortes pasivos facultativos no contestan la demanda y otros la contestan, la admisión tácita solo podrá efectuarse respecto de los que no contestaron, mas no respecto de los pasivos que sí contestaron.

En nuestro concepto la respuesta ofrece ciertos matices. Si los hechos que constituyen la causa de pedir de las pretensiones reclamadas de cada uno de los litisconsortes pasivos facultativos tienen plena autonomía, resultará posible tener por tácitamente admitidos esos hechos respecto del que no contestó, mas no respecto del litisconsorte pasivo que sí contestó, debiendo recibirse la causa a prueba respecto de aquel que contestó la demanda ${ }^{34}$. Por el contrario, si tales hechos tienen conexión o son los mismos invocados para todos o algunos de los litisconsortes pasivos y el que contestó la demanda los controvirtió, no resulta posible aplicar la admisión tácita por no contestación de la demanda, toda vez que, se estaría afectando a la parte que sí contestó, extendiéndose indebidamente la admisión tácita, lo que perjudicaría a la parte que sí cumplió con la carga procesal oportunamente ${ }^{35}$.

${ }^{33}$ Arazi (1995), p. 122; Romero (2000), p. 64; CARrasco (2010), pp. 70-71, quien sostiene: "puede que la actitud que toma cada uno de los litisconsortes le favorezca o perjudique solamente a él, cuestión que perfectamente es posible porque el litisconsorcio voluntario permite que haya distintas soluciones para cada litisconsorte, es decir, uno de ellos puede ganar el pleito, y el otro perderlo".

${ }^{34}$ Véase una aplicación en la jurisprudencia de esta figura en: Vargas con Construcciones Luis Antonio Pinochet Vera y otra (2016).

${ }^{35}$ Aquel sería precisamente el caso, por ejemplo, de una demanda por despido injustificado en contra de una contratista (empleador directo) y su mandante, donde precisamente no contesta la demanda el demandado principal y la mandante controvierte 
Así, la normativa legal y la indivisibilidad de los hechos, hacen necesario en esta última situación recibir la causa a prueba respecto de todos los litisconsortes pasivos facultativos, no pudiendo utilizarse la admisión tácita.

\section{No concurrencia del demandado a la audiencia preparatoria o única}

$\mathrm{El}$ art. $453 \mathrm{~N}^{\circ} 1$ inc. $7^{\circ}$ del Código del Trabajo no exige para que se tengan por tácitamente admitidos los hechos afirmados en la demanda que el demandado no concurra a la(s) audiencia(s) del procedimiento respectivo. Por tanto, sea que concu rra o no concurra a la audiencia respectiva, el juez puede ejercer la prerrogativa contemplada en la norma señalada ${ }^{36}$. Ello porque lo que exige la disposición en cuestión es que el demandado no conteste en tiempo y forma, no exigiendo ningún otro requisito adicional. Exigir como requisito adicional a la demanda, citación y notificación de la misma y falta de contestación, que el demandado no concurra personalmente o asistido por abogado habilitado a la audiencia respectiva, es agregar una exigencia no contemplada en la legislación laboral para la admisión tácita de los hechos por no contestación de la demanda.

Sin embargo, a pesar de la claridad del art. $453 \mathrm{~N}^{\circ} 1$ inc. $7^{\circ}$ alguna jurisprudencia aislada ha exigido para que opere la admisión tácita por no contestación que la parte demandada no concurra a la audiencia respectiva, ni personal ni representado por abogado habilitado. A contrario sensu, según esta jurisprudencia judicial, si el demandado concurre personal o debidamente asistido y niega en la audiencia correspondiente los hechos afirmados en la demanda no resulta posible tenerlos por tácitamente $\operatorname{admitidos}^{37}$. De ahí que si el juez de la instancia tiene por tácitamente admitidos los hechos afirmados en el libelo incurre -en opinión de esta postura- en infracción de la garantía del debido proceso, al vulnerar el art. $453 \mathrm{~N}^{\circ} 1$ inc. $7^{\circ}$ del Código del Trabajo ${ }^{38}$. Posición que no resulta ajustada, porque, según se indicó, agrega un requisito no establecido por el legislador laboral, careciendo de un sustento normativo que permita sustentarla ${ }^{39}$.

el despido. Sería, por tanto, injusto para la parte diligente que se le impusiese como un hecho admitido -que el despido se produjo en los términos como alega el actor- por no haber contestado el demandado principal y ex empleador del demandante.

${ }^{36}$ Rugel con Bastías (2016); Fuentes con Construmart S.A. (2016).

${ }^{37}$ Navarrete con MM Construcciones E.I.R.L. (2014); Donaire y otros con Administradora de Supermercado (2015); SCM Lumina Copper con Inspección Provincial del Trabajo de Copiapó (2016).

${ }^{38}$ Ibid.

${ }^{39}$ Cabe destacar a este respecto que la ley $\mathrm{N}^{\circ} 20.087$ establecía originalmente en el inc. $3^{\circ}$ del $\mathrm{N}^{\circ}$ 1) del art. 453 del Código del Trabajo lo siguiente: "Cuando el demandado 


\section{Oportunidad procesal para hacer efectiva la admisión tácita por no contestación de la demanda}

Todo el proceso laboral se encuentra regido por el principio de legalidad, pudiendo el juez, a consecuencia del mismo, hacer solo aquello que le permite la legislación y en la oportunidad que la misma señala (arts. 6, 7 y $19 \mathrm{~N}^{\circ} 3$ inc. $6^{\circ}$ de la Constitución Política). Más aún cuando existe un estricto sistema de preclusiones en el proceso laboral, en virtud del cual transcurrida la oportunidad prevista por el Código del Trabajo para realizar un acto procesal no se puede realizar posteriormente, so pena de incurrir en un vicio de nulidad.

Atendido que el juez laboral se rige por el principio de legalidad resulta importante determinar la oportunidad en que puede hacer efectiva la admisión tácita de los hechos afirmados en la demanda por no contestación de la demanda. Al respecto no existe una opinión unánime sobre cuál es la oportunidad, existiendo dos posiciones en la doctrina y en la jurisprudencia judicial nacional.

a) Para una postura -mayoritaria en la jurisprudencia- la admisión tácita corresponde utilizarla -si decide hacerlo el juez- en la audiencia preparatoria (o audiencia única, tratándose del procedimiento monitorio $^{40}$ ) antes de recibir la causa a prueba, dictándose sentencia definitiva en ese instante, no siendo necesario continuar con el desarrollo normal del proceso diseñado por el Código del Trabajo. Si el juez no hace uso de la admisión tácita antes de recibir la causa a prueba y procede a recibirla, fijando los hechos a ser probados, admitiendo a las partes ofrecer y rendir prueba, no podrá hacerlo posteriormente, por haber precluido la oportunidad en que tenía para hacerlo.

La razón de que la admisión tácita debe hacerse efectiva antes de la recepción de la causa a prueba, radica en que todos los hechos afirmados en la demanda son pacíficos ${ }^{41}$, por no controvertir el demandado rebelde

no concurriere a la audiencia preparatoria, o de hacerlo no negare en su contestación algunos de los hechos contenidos en la demanda, el juez, en la sentencia definitiva, podrá estimarlos como tácitamente admitidos". De esta forma, era entendible que con esta redacción la doctrina judicial citada en los dos números anteriores pudiese interpretar como procedente el requisito de no comparecer en la audiencia preparatoria, más con la modificación introducida por la ley $\mathrm{N}^{\circ} 20.260$ en la actual redacción del art. 453 del Código del Trabajo, no puede admitirse una interpretación que imponga como requisito la comparecencia del demandado a la audiencia respectiva.

${ }^{40}$ Orellana con Rivera (2016); Etura con Penta Vida Compañía de Seguros Vida S.A. (2016); Orellana con Círculo Español de Santiago (2016); Bianchi con Ilustre Municipalidad de Iquique (2016).

${ }^{41}$ En el litisconsorcio pasivo facultativo, en los casos en que procede la admisión tácita por no contestación de alguno de los litisconsortes pasivos, concluirá el proceso res- 
ningún hecho, al no haberla contestado; la misma impide recibir la causa a prueba, por no existir hechos controvertidos. De ahí que el legislador laboral introdujera en el art. $453 \mathrm{~N}^{\circ} 3$ del Código del Trabajo, el inc. $2^{\circ}$, el cual señala: "De no haber hechos sustanciales, pertinentes y controvertidos, el tribunal dará por concluida la audiencia y procederá a dictar sentencia”. Esta norma se encuentra reservada para aquellos supuestos en que no existe hecho controvertido alguno, habilitando al juez para dictar sentencia definitiva luego de la etapa procesal de conciliación, siendo uno de ellos la admisión tácita total. Así lo sostiene un sector de la doctrina nacional ${ }^{42}$. Criterio que es compartido también por la jurisprudencia judicial mayoritaria ${ }^{43}$.

Para estos efectos, la admisión tácita constituye un supuesto de exención de prueba, por lo que no sería necesario recibir la causa a prueba respecto del demandado rebelde, dictándose sentencia definitiva a su respecto sin necesidad de recibir la causa a prueba.

A favor de esta posición pueden indicarse diversos argumentos legales, además, de los ya expuestos.

En primer lugar, la ubicación de la norma que consagra la admisión tácita en el Código del Trabajo. Entre las reglas que el juez debe aplicar en la audiencia preparatoria establecidas en el art. 453 del Código del Trabajo podemos encontrar la que regula la admisión tácita, la que está ubicada 106 antes que las que contempla la etapa probatoria, cuya regulación se encuentra a partir del $\mathrm{N}^{\circ} 3$ del art. 453; lo que revela que su aplicación opera antes de las reglas que regulan la etapa probatoria ${ }^{44}$.

pecto de los que no contestaron la demanda y continuará solamente respecto de los que contestaron la demanda. Es por ello que la admisión tácita por no contestación de la demanda es, igualmente, total para los litisconsortes pasivos rebeldes.

${ }^{42}$ Carrasco (2010), p. 124; Fernández (2011a), p. 234.

${ }^{43}$ En este sentido: Rezzio con Ilustre Municipalidad de Santiago (2012); Espinoza y otro con Decorados Industriales S.A. (2012); Peralta con Transportes Nazca Limitada y otra (2013); Mamani con Ilustre Municipalidad de Camiña (2013); Ulloa con Rolke (2013); Alarcón con Inversiones Colina S.A. (2013); Ogaz con PG Proyectos y Prosegur Chile S.A. (2013); Bustamante con Servicios Integrales C y C Ltda. (2013); Prosegur Chile S.A. con Llanos y otros (2014); González con Comercial Berta Fernández Limitada (2014); Aranda y otros con Comercial Liquiplast Ltda. y otras (2015); Ludueña con Aguirre (2015); Arteaga con Transportes Carlos Abarca Limitada (2015); Contreras con Makluf (2015); Servicios Generales Fullclean con Pulido (2015); Montaño con Human Resources II S. A. (2015); Moreno con Soldaduras y Estructuras Lucero y Rivera Ltda. y otra (2015); Martínez con Genco S.A. (2015); Contreras con Inversiones Flores y Cortés Limitada (2015); Celedón con Construcciones Benavente Ltda. (2016); Toro con Rivera (2016); Orellana con Rivera (2016); Rollino con Constructora Ecisa Chile S.A. (2016); Canepa con Gendarmería de Chile (2016); Rugel con Bastias (2016); Orellana con Termolaminados Ltda. (2016); Fuentes con Construmart S.A. (2016); Etura con Penta Vida Compañía de Seguros Vida S.A. (2016); Cox con Vásquez (2016); Paris Administradora Ltda. con Robles (2016); Orellana con Círculo Español de Santiago (2016).

${ }^{44}$ González con Figueroa (2013). 
Lo anterior se encuentra en perfecta armonía con la idea de que la etapa probatoria es eventual, desde que solo procederá si existen hechos sustanciales, pertinentes y controvertidos. De no existir hechos controvertidos no tendrá lugar la etapa probatoria, por ser innecesaria, correspondiendo dictar sentencia definitiva (art. $453 \mathrm{~N}^{\circ} 3$ inc. $2^{\circ}$ del Código del Trabajo).

En segundo lugar, los principios de celeridad y economía procesal que rigen en los procedimientos laborales rechazan los trámites innecesarios y promueven que estos concluyan en el menor tiempo, con los mínimos actos procesales posibles; objetivo al que contribuye -precisamente- la admisión tácita por falta de contestación de la demanda hecha efectiva antes de la recepción de la causa a prueba.

Con todo, la principal duda que provoca esta forma de entender la admisión tácita total tiene relación con si su ejercicio en la audiencia preparatoria (o única, tratándose del procedimiento monitorio) vulnera la garantía del debido proceso del demandado en su manifestación del derecho a defensa y derecho a la prueba, entendido este último como la posibilidad que tiene de ofrecer prueba, que la misma sea admitida, rendida y valorada, para desvirtuar los hechos afirmados por el demandante.

La Corte Suprema ${ }^{45}$ y el Tribunal Constitucional ${ }^{46}$ analizando este problema concluyen que no existe vulneración del debido proceso, desde que el proceso laboral donde se ha instaurado la admisión tácita por no contestación de la demanda, cuya eficacia es omitir la recepción de la causa a prueba por no existir hechos que deban ser probados,

"aparece tan compatible con las reglas del debido proceso como puede serlo el que atribuye otros efectos jurídicos al silencio estimando que hay controversia cuando nada dice el demandado. Aún más, puede entenderse que se vincula mayormente con el sentido natural de las cosas, manifestado en el aforismo "el que calla, otorga" $"$.

Se respeta la garantía constitucional del debido proceso de que es titular el demandado, porque se le confiere por la legislación laboral la posibilidad concreta para defenderse. Primero, mediante la contestación de la demanda realizada en tiempo y forma. Luego, si contestó cumpliendo las exigencias legales, a través del ofrecimiento, admisión, recepción y valoración de la prueba rendida relevante para acreditar los hechos controvertidos que son de su carga. El debido proceso exige la tramitación conforme a las exigencias legales y, ejercerse la admisión tácita en la

${ }^{45}$ Artigas con Corporación de Asistencia Judicial (2014).

${ }^{46}$ Tribunal Constitucional, 14 de mayo de 2009, rol 1384-2009.

${ }^{47}$ Ibid.; Artigas con Corporación de Asistencia Judicial (2014). 
audiencia preparatoria (audiencia única en el procedimiento monitorio) se ajusta a la ley, porque es una posibilidad reconocida por el Código del Trabajo, guardando coherencia con la Constitución Política de la República ${ }^{48}$.

b) Para una segunda posición doctrinaria y jurisprudencial, la admisión tácita por no contestación de la demanda no permite omitir la recepción de la causa a prueba, desde que solo se podrá ejercer por el juez, si decide hacerlo, en "la sentencia definitiva", tal como lo señala el art. $453 \mathrm{~N}^{\circ} 1$ inc. $7^{\circ}$ del Código del Trabajo, entendiendo por tal únicamente la dictada dentro del plazo establecido en el art. 457 del Código del Trabajo ${ }^{49}$ luego de concluida la audiencia de juicio ${ }^{50}$, cuyo contenido está contemplado en el art. 459 del mismo Código ${ }^{51}$. Esta posición solamente admite utilizar la admisión tácita en la sentencia definitiva dictada al término del procedimiento llevado a cabo siguiendo todas las etapas procesales establecidas por el Código del Trabajo ${ }^{52}$.

Esta posición se sustenta en diversos argumentos. El primero de ellos es que, si la parte demandada no contesta no puede ser privada de su derecho a rendir prueba, más aún cuando existe texto legal que obliga a rendirla cuando existen hechos sustanciales, pertinentes y controvertidos; siendo una de estas hipótesis aquella en que el demandado no contesta. Aquello se debe a que atribuye a la falta de contestación de la demanda el mismo efecto que se establece en el art. 313 del Código de Procedimiento Civil en el proceso civil; es decir, la contestación ficta de la demanda ${ }^{53}$, debiendo tener el juez por controvertidos los hechos afirmados en el libelo, por ser ese el efecto de la contestación ficta. Lo anterior, debido a que esta posición sostiene que, por aplicación supletoria a los procedimientos de

${ }^{48}$ Ulloa con Rolke (2013), sentencia que resuelve: “Octavo: Que, de los antecedentes de autos resulta que no se advierte vulneración de las garantías que denuncia el recurrente, toda vez que se han cumplido todos los trámites establecidos por la ley para la sustanciación del proceso y la decisión del tribunal ha sido adoptada en uno legalmente tramitado, resolviendo de acuerdo a la normativa legal aplicable"; Rugel con Bastias (2016); Orellana con Termolaminados Ltda. (2016); Paris Administradora Ltda. con Robles (2016); Bianchi con Ilustre Municipalidad de Iquique (2016).

${ }^{49}$ En el caso del procedimiento monitorio, luego de concluida la audiencia única, conforme al art. 500 del Código del Trabajo.

${ }^{50}$ En este sentido: Lay con Agencia de Aduana Jorge Correa (2012), Urriola con Banco del Estado de Chile (2012), Hernández con Sociedad Agrícola Alborada S.A. (2014), Riquelme con Transportes Artisa Limitada (2014), Navarro con Verdugo (2014), Cevallos con MUT Gestión Móvil S.A. (2014), Llano con Prosegur Ltda. (2014), Silva con Santibáñez (2016), Flores con Delta Ingeniería y Construcción S.A. (2016), Icka con Ilustre Municipalidad (2016), Chan con Flex Chile Limitada (2016), Pons con Ríos (2016).

${ }^{51}$ Para esta posición, tratándose del procedimiento monitorio, la admisión tácita solamente podrá utilizarse al concluirse la audiencia única de conciliación, contestación y prueba, en la sentencia dictada en conformidad al art. 500 del Código del Trabajo.

${ }^{52}$ Aránguiz (2011), p. 88.

${ }^{53}$ Palavecino (2010a), pp. 7-8. 
aplicación general, tutela laboral y monitorio de las normas contenidas en los libros I y II del Código de Procedimiento Civil, corresponde aplicar a estos el art. 313 del Código de Procedimiento Civil, debiéndose necesariamente recibir la causa a prueba cuando el demandado no contesta.

El segundo argumento consiste en que, si se ejerce la admisión tácita en la audiencia preparatoria o única, según sea el procedimiento en que tenga lugar, omitiéndose la recepción de la causa a prueba, no se ejerce en la oportunidad procesal correspondiente, que es la contemplada para la dictación de la sentencia definitiva luego de rendida la prueba, anticipándose una decisión reservada exclusivamente para el fallo decisorio ${ }^{54}$.

Si no se contesta la demanda, según esta segunda posición, necesariamente debe recibirse la causa a prueba, admitirse aquella ofrecida e incorporarse en la oportunidad procesal correspondiente. Por tanto, si el juez ejerce la admisión tácita en la audiencia preparatoria o en la audiencia única (procedimiento monitorio), no recibiéndose la causa a prueba, se priva al demandado de ofrecer y rendir prueba, vulnerándose la garantía del debido proceso $^{55}$, que exige que toda sentencia definitiva debe fundarse en un proceso legalmente tramitado, siendo uno de sus elementos más significativos el otorgamiento a las partes de la posibilidad de ser oídos, de ofrecer y rendir prueba para acreditar los presupuestos fácticos de sus defensas y que dicha prueba sea valorada en conformidad al art. 456 del Código del Trabajo $0^{56}$.

De ahí que, cuando se hace efectiva la admisión tácita de los hechos en la audiencia preparatoria, se han acogido algunos recursos de nulidad fundado en el motivo de nulidad de infracción de garantías constitucionales previsto en el art. 477 inc. $1^{\circ}$ del Código del Trabajo, concretamente por vulneración de la garantía del debido proceso, ordenándose la realización de una nueva audiencia preparatoria en que se reciba la causa a prueba ${ }^{57}$, por sostenerse que la admisión tácita debió ejercerse en la sentencia definitiva dictada en la oportunidad prevista en el art. 457 del Código del Trabajo.

Esta segunda posición es acorde con la regla de prudencia que hace aconsejable que la valoración del silencio del demandado al no contestar, al igual que sucede con el tratamiento de ciertas presunciones fundadas en la conducta de las partes (confesión ficta, exhibición de documentos), se posponga a la fase de la sentencia definitiva dictada en la oportunidad prevista por el legislador luego de concluido todo el procedimiento que ha diseñado,

${ }^{54}$ Aránguiz (2011), pp. 88-89; Urriola con Banco del Estado de Chile (2012).

${ }^{55}$ Palavecino (2010a), p. 7; Aránguiz (2011), p. 89.

${ }^{56}$ En este sentido: Lay con Agencia de Aduana Jorge Correa (2012), Urriola con Banco del Estado de Chile (2012), Hernández con Sociedad Agrícola Alborada S.A. (2014), Navarro con Verdugo (2014), Flores con Delta Ingeniería y Construcción S.A. (2016), Chan con Flex Chile Limitada (2016), Pons con Ríos (2016).

${ }^{57}$ Ibid. 
ya que a lo largo del pleito pueden advertirse correctamente determinadas circunstancias que demuestren que a pesar del silencio del demandado, los hechos sucedieron en la realidad de una manera distinta a la señalada por el actor en su demanda, que conllevan al juez a rechazar la admisión tácita ${ }^{58}$.

Atendida la solidez de los argumentos que sustentan la primera posición, somos partidarios de que la admisión tácita por no contestación de la demanda debe hacerse efectiva luego de fracasada la etapa de conciliación, si el juez decide utilizarla, omitiendo la recepción de la causa a prueba. Respuesta que, además, guarda conformidad con el principio dispositivo, que tiene amplia vigencia en el proceso laboral ${ }^{59}$, puesto que de acuerdo con el mismo las partes no solo tienen la carga de introducir los hechos que constituyen la causa de pedir de sus pretensiones al proceso sino, también, la de controvertir los hechos de la otra parte o mostrar su aceptación con los $\operatorname{mismos}^{60}$. De este modo, no se necesita prueba cuando no existen hechos controvertidos, debiendo el juez conformarse a los hechos pacíficos.

En la admisión tácita total, al no existir contestación de la demanda, el demandando no cumplió con su carga procesal de contestar, ni menos con la carga de controvertir expresamente los hechos afirmados por el actor en el libelo, constituyendo su silencio una aceptación tácita de los hechos que constituyen la causa de pedir de las pretensiones del actor, 110 no existiendo hechos controvertidos. Es la no existencia de hechos controvertidos producto de la admisión tácita por no contestación la que impide pasar a la fase de prueba, dándose por concluido el procedimiento, debiéndose dictar sentencia definitiva de inmediato.

Si el juez no hace uso de la admisión tácita luego de la etapa de conciliación y procede a recibir la causa a prueba, no podrá hacerlo en la sentencia definitiva dictada luego de la etapa de prueba, por haber precluido la etapa procesal que tenía para hacerlo.

\section{NATURALEZA JURÍDICA Y EFECTOS DE LA ADMISIÓN TÁCITA POR NO CONTESTACIÓN DE LA DEMANDA}

El art. $453 \mathrm{~N}^{\circ} 1$ inc. $7^{\circ}$ del Código del Trabajo no precisa los efectos de la admisión táctica por no contestación de la demanda, limitándose a establecer

${ }^{58}$ MuÑoz (2001), pp. 145-146.

${ }^{59}$ Diversas sentencias judiciales reconocen el principio dispositivo en el proceso laboral. A modo de ejemplo: G4S Security Services Regiones con Inspección Provincial del Trabajo de Antofagasta (2013), Águila con Empresa Trancura Ingeniería y Construcción Limitada (2014), Seil E \& C CO Ltd. Con Donoso (2016), Cabello con Servicios Industriales Integra Limitada (2016), Morales con Productos Fernández S.A. (2016).

${ }^{60}$ Fernández (2011a), p. 22; Fernández (2011b), p. 42. 
que el juez "podrá" tener por tácitamente admitidos los hechos afirmados en la demanda en "la sentencia definitiva"; imprecisión que ha generado discrecionalidad judicial en su utilización y opiniones divergentes en la interpretación de la norma, lo que hace necesario precisar los efectos de la admisión tácita y su alcance.

Como primera cuestión debe señalarse que la naturaleza jurídica y efectos de la admisión táctica de los hechos por no contestación es de lo más controvertido tanto en doctrina ${ }^{61}$ como en el ámbito de la jurisprudencia judicial.

La discusión principal reside en determinar si la admisión tácita por no contestación constituye un relevo de prueba en beneficio del demandante o, por el contrario, de todas formas debe recibirse la causa a prueba, fijándose los hechos sustanciales, pertinentes y controvertidos, constituyendo la admisión tácita solo un antecedente probatorio a considerarse en la sentencia definitiva, lo que equivale a decir que la rebeldía del demandado produce la contestación ficta. En términos más generales, la discusión se centra en establecer si el juez debe o no recibir la causa a prueba si decide ejercer la facultad contemplada en el art. $453 \mathrm{~N}^{\circ} 1$ inc. $7^{\circ}$ del Código del Trabajo como consecuencia de la no contestación de la demanda, existiendo opiniones diferentes.

Una segunda cuestión, estrechamente vinculada a la anterior, es aquella que tiene relación con el carácter que tiene la admisión tácita para el juez y para las partes, debiendo establecerse si la misma constituye una facultad, deber u obligación para el juez como también si es una sanción o consecuencia del incumplimiento de una carga procesal para el demandado. Todos aspectos que serán tratados separadamente:

\section{Omisión de la recepción de la causa a prueba. Relevatio ab onere probandi}

Para una primera posición -que es mayoritaria en la jurisprudencia judicial- la admisión tácita por no contestación autoriza al juez a decidir la

${ }^{61}$ Un sector de la doctrina nacional sostiene que la no contestación produce la contestación ficta de la demanda, pudiendo el juez solamente ejercer la admisión tácita luego de recibida la causa a prueba y rendida la prueba admitida. En este sentido: ARÁNGUIZ (2011), pp. 88-89; PALAvecino (2010a), pp. 7-8. Incluso más, se niega por un autor que la no contestación de la demanda constituya un supuesto de admisión tácita, por el contrario, sostiene que es una ficta litis contestatio. Cfr. ZePEDA (2013), pp. 202-204, 214-215.

En cambio, otro sector de la doctrina sostiene que la admisión tácita por no contestación de demanda si se decide ejercer por el juez debe efectuarse en la audiencia preparatoria o única, según el procedimiento en que tenga lugar, omitiendo recibir la causa a prueba, dictando sentencia definitiva de inmediato. Cfr. CARRASCO (2010), pp. 124-125; FERnÁndez (2011a), pp. 232-235. 
controversia sin necesidad que se rinda prueba ${ }^{62}$. La admisión tácita total originada como consecuencia de la no contestación, produce -según esta opinión- una relevatio ab onere probandi en favor de la parte que originalmente tenía la carga de probar, gozando el demandado de aquello que en el Common Law llaman benefit of assumption ${ }^{63}$. Debido a que no existe hecho controvertido, la admisión tácita no es per se fuente o medio de prueba, siendo su efecto la exoneración de prueba. La admisión tácita total no da lugar a rendir prueba dirigida a demostrar los hechos afirmados; ello porque los hechos afirmados en la demanda se tienen por pacíficos como consecuencia de la admisión tácita ${ }^{64}$.

Es así como la no contestación de la demanda puede reputarse como suficiente para excluir los hechos afirmados en ella del thema probandum, constituyendo la conducta omisiva del demandado un acto procesal mediante el cual se da por reconocida implícitamente la verdad de los hechos expuestos por el demandante, quedando, por ello, relevado de acreditar los hechos admitidos, resultando innecesario la rendición de cualquier medio de prueba sobre los mismos ${ }^{65}$. Es por esto que se sostiene que la

${ }^{62}$ En este sentido: Rezzio con Ilustre Municipalidad de Santiago (2012), Espinoza y otro con Decorados Industriales S.A. (2012), Peralta con Transportes Nazca Limitada y otra (2013), Mamani con Ilustre Municipalidad de Camiña (2013), Ulloa con Rolke (2013), Alarcón con Inversiones Colina S.A. (2013), Ogaz con PG Proyectos y Prosegur Chile S.A. (2013), Bustamante con Servicios Integrales C y C Ltda. (2013), Prosegur Chile S.A. con Llanos y otros (2014), González con Comercial Berta Fernández Limitada (2014), Aranda y otros con Comercial Liquiplast Ltda. y otras (2015), Ludueña con Aguirre (2015), Arteaga con Transportes Carlos Abarca Limitada (2015), Contreras con Makluf (2015), Servicios Generales Fullclean con Pulido (2015), Montaño con Human Resources II S.A. (2015), Moreno con Soldaduras y Estructuras Lucero y Rivera Ltda. y otra (2015), Martínez con Genco S.A. (2015), Contreras con Inversiones Flores y Cortés Limitada (2015), Celedón con Construcciones Benavente Ltda. (2016), Toro con Rivera (2016), Orellana con Rivera (2016), Rollino con Constructora Ecisa Chile S.A. (2016), Canepa con Gendarmería de Chile (2016), Rugel con Bastias (2016), Orellana con Termolaminados Ltda. (2016), Fuentes con Construmart S.A. (2016), Etura con Penta Vida Compañía de Seguros Vida S.A. (2016), Cox con Vásquez (2016), Paris Administradora Ltda. con Robles (2016); Orellana con Círculo Español de Santiago (2016), Bianchi con Ilustre Municipalidad de Iquique (2016).

${ }^{63}$ Sapone (2012), p. 15; Farolfi (2015), p. 127.

${ }^{64}$ CARrasco (2010), p. 128, quien señala: "A nuestro entender, la admisión de los hechos libera o redime a la parte a quien favorece de probar los hechos constitutivos de su pretensión o de su reacción, es decir, juega un papel de relevo de prueba y no de inversión de la carga de la prueba, cuestión que impide discutir los mismos en una fase probatoria posterior”. En similares términos el mismo autor en CARRASCO (2010), pp. 137-138.

${ }^{65}$ Artigas con Corporación de Asistencia Judicial (2014). En esta sentencia recaída en recurso de unificación de jurisprudencia la Corte Suprema sostiene: " $5^{\circ}$ Que, por consiguiente, existen interpretaciones disímiles sobre una misma materia de derecho, en lo concerniente a determinar si el juez en virtud de la potestad consagrada en el artículo 453 número 1, inciso 7, del Código del Trabajo puede omitir la recepción de la causa a 
admisión de los hechos tiene una función de relevo de prueba y no de inversión de la carga de la prueba ${ }^{66}$.

Ahora bien, debe precisarse que a pesar de que el nombre de ficta confessio que se le otorga a la admisión tácita por no contestación de la demanda por parte de algunos autores ${ }^{67}$, la misma no constituye el medio de prueba denominado prueba confesional, porque este, a diferencia de la admisión tácita total, tiene como presupuesto que la causa se haya recibido a prueba y, por tanto, que se hayan admitido y rendido medios de pruebas, dictándose la sentencia definitiva en los plazos establecidos en los arts. 457 y 500 del Código del Trabajo, según el procedimiento en que haya recaído. En cambio, la admisión tácita total de los hechos como relevo de prueba, implica que no existen hechos controvertidos, impidiendo las fases de discusión y prueba, las que son innecesarias ${ }^{68}$; distinción que tanto la doctrina nacional ${ }^{69}$ como extranjera ${ }^{70}$ han demostrado con acierto.

Asimismo, la admisión de los hechos como relevo de prueba es distinta al allanamiento, existiendo numerosos aspectos que diferencian a ambas instituciones, no siendo admisible su confusión ${ }^{71}$.

prueba o debe necesariamente recibirla, cuando el demandado nada ha dicho sobre los hechos expuestos en la demanda o, si lo hizo, lo fue en forma extemporánea; por lo que corresponde que esta Corte establezca cuál es la correcta, y, para ello, es pertinente tener presente que la citada disposición legal prescribe, lo siguiente: 'Cuando el demandado no contestare la demanda, o de hacerlo no negare en ella algunos de los hechos contenidos en la demanda, el juez, en la sentencia definitiva, podrá estimarlos como tácitamente admitidos'. Dicha norma legal consagra la institución de carácter procesal que la doctrina denomina 'admisión de hechos', que puede ser expresa o tácita, y, la primera, se puede definir como un acto procesal por el cual una parte reconoce la verdad de los hechos expuestos por la contraria y cuyo efecto consiste en que ésta queda relevada de probar los hechos admitidos por la primera, resultando innecesaria cualquier forma de prueba de los mismos que el juez debe tener por acreditados. La admisión tácita provoca el mismo efecto, pero se diferencia de la expresa porque solo cabe aplicarla en los casos que señala la ley; y uno de aquellos es precisamente el que contempla la norma transcrita precedentemente". En similares términos: Tribunal Constitucional, 14 de mayo de 2009, rol 1384-2009. Igualmente, parte de la doctrina Carrasco (2010), p. 128; Fernández (2011a), p. 234; Delgado (2014), p. 516.

${ }^{66}$ Carrasco (2010), p. 128; SAPOne (2012), pp. 15-16; FAROlfi (2015), p. 127; Tribunal Constitucional, 14 de mayo de 2009, rol 1384-2009; Artigas con Corporación de Asistencia Judicial (2014).

${ }^{67}$ Orellana y Pérez (2007), pp. 20-23; Silva (2009), pp. 65-71.

${ }^{68}$ De hacer el juez uso de la aceptación tácita de los hechos afirmados en la demanda debido a la no contestación del demandado, no le está permitido diferenciar cuáles admite y cuáles no, ya que al no hacerlo la ley, tampoco le corresponde realizar esa tarea al órgano jurisdiccional. En este sentido: Arévalo con Labrador Ltda. (2011).

${ }^{69}$ CARrasco (2010), pp. 128-129; Fernández (2011a), pp. 234-235.

${ }^{70}$ Devis (1972), p. 191.; Lessona (1928), p. 210; Bachmaier (1994), p. 288; De La Oliva y Fernández (1995), p. 305; Montero (2006), p. 81.

${ }^{71}$ Se han expuesto como diferencias entre la admisión de los hechos y el allanamiento: “a) El allanamiento sólo lo puede realizar el demandado mientras la admisión de los hechos 
En fin, para un sector de la doctrina nacional y la jurisprudencia judicial mayoritaria, la admisión tácita total releva de la carga de la prueba al demandante, constituyendo un supuesto de omisión del thema probandum, no debiéndose recibir la causa a prueba, procediendo el juez a dar por concluida la audiencia respectiva sin necesidad de recibir la causa a prueba y dictar sentencia definitiva de inmediato. Ello, debido a que el demandado al no contestar aceptó la verdad de los hechos expuestos, quedando solo como cuestión a resolver la jurídica, la que se realiza precisamente en la sentencia definitiva que se dicte, acogiéndose o rechazándose las pretensiones del demandante, según si el juez las estima o no ajustadas a derecho ${ }^{72}$.

\section{La admisión tácita como antecedente probatorio para acreditar los hechos controvertidos}

Otro sector de la doctrina ${ }^{73}$ y jurisprudencia nacional ${ }^{74}$ sostiene que la admisión tácita de los hechos derivada de la no contestación no excluye a los hechos afirmados en la demanda del thema probandum ni determina un relevatio ab onere probandi, ni menos una inversión de la carga de la prueba.

puede hacerse por ambas partes; b) la admisión de los hechos por el demandado, aunque se refiera a todos los hechos alegados por el actor y no vaya acompañado de formulaciones de defensas, sólo tiene como consecuencia hacer innecesario la prueba de esos hechos, pero no conduce necesariamente a una sentencia estimatoria, en cambio el allanamiento importa una sentencia favorable al actor; c) Como consecuencia de lo anterior, la admisión de hechos, como su nombre lo indica, se refiere a los hechos, en cambio el allanamiento se refiere a la pretensión procesal, y d) la admisión de hechos puede ser tácita o expresa, mientras que el allanamiento debe ser expreso", CARRASCO (2010), p. 127. En igual sentido: ORTELls (2007), pp. 451-452.

${ }^{72}$ Carrasco (2010), p. 129, señala: “[...] el hecho que un tribunal pueda tener por admitidos tácitamente los hechos expuestos en la demanda, en virtud de la rebeldía del demandado en contestarla, no implica la obtención de una sentencia estimatoria, ello porque el juez debe analizar el elemento jurídico de la pretensión deducida (causa de pedir) si el petitum del libelo del actor es posible de ser reconocido o tutelado jurídicamente (accionabilidad de la acción deducida)"; Aguirre con Sociedad de Servicios Médicos (2013), Bastías con Inversiones Tirúa S.A. (2013), Canepa con Gendarmería de Chile (2016), Rojas con Transporte y Maquinaria B y B (2016).

${ }^{73}$ Palavecino (2010a), pp. 7-8; Aránguiz (2011), pp. 88-89.

${ }^{74}$ En este sentido: Lay con Agencia de Aduana Jorge Correa (2012), Urriola con Banco del Estado de Chile (2012), Hernández con Sociedad Agrícola Alborada S.A. (2014), Riquelme con Transportes Artisa Limitada (2014), Navarro con Verdugo (2014), Cevallos con MUT Gestión Móvil S.A. (2014), Llano con Prosegur Ltda. (2014); Silva con Santibáñez (2016), Calderón con Condominio Los Veleros (2016), Flores con Delta Ingeniería y Construcción S.A. (2016), Icka con Ilustre Municipalidad (2016), González con Ingeaustral Limitada (2016), Chan con Flex Chile Limitada (2016), Pons con Ríos (2016). 
En efecto, la admisión tácita total, según esta posición, ofrece al juez una regla de prueba libremente valorada en la sentencia definitiva, un instrumento para formarse el convencimiento sobre los hechos alegados por el demandante.

La admisión tácita total por no contestación de la demanda constituye un verdadero antecedente probatorio que debe ser valorado por el juez al momento de dictar la sentencia definitiva pronunciada en la oportunidad prevista en el art. 457 del Código del Trabajo, tratándose del procedimiento de aplicación general o de aquellos tramitados conforme a las reglas de este, y la dictada en la oportunidad establecida en el art. 500 del mismo Código respecto del procedimiento monitorio.

Se utiliza la admisión tácita como medio de adquisición de la información mediante la cual el juez puede valerse para verificar la realidad de los hechos controvertidos. Constituye un instrumento informativo del cual el juez extrae elementos útiles para la formación de su convencimiento.

Si se toma la prueba en su acepción de dato cognoscitivo, la admisión tácita constituye una prueba ${ }^{75}$. La misma no tiene un contenido informativo, pero sí un valor demostrativo, de medio de convencimiento (de elemento útil para la formación del convencimiento) del juez ${ }^{76}$.

El juez puede formarse su convencimiento utilizando dos elementos de conocimiento distintos ${ }^{77}$.

El primer elemento está constituido por la prueba de carácter tradicional, propuesta por las partes o el juez y rendida en el proceso, la que constituye un elemento propiamente informativo, introduciendo información, datos fácticos al proceso.

El segundo elemento de conocimiento está constituido por la admisión tácita, que está ontológicamente constituida por un simple comportamiento del demandado al que la ley le atribuye una idoneidad cognoscitiva. A su vez, viene atribuida a la admisión tácita por no contestación la función de instrumento eurístico, o sea, de un medio del cual se sirve el juez para establecer la verdad de los hechos afirmados en la demanda, los que pueden ser demostrados en el proceso mediante un instrumento que per $s e$ no es informativo. Eficacia probatoria que, igualmente, encuentra su razón de ser en la regla de la experiencia según la cual la parte que tiene interés en negar la verdad de un hecho contesta el hecho allegado por la contraparte al proceso, razón por la cual es plausible inferir de tal comportamiento omisivo una confirmación de la verdad del hecho afirmado por el demandante ${ }^{78}$.

\footnotetext{
${ }^{75}$ SAPONe (2012), pp. 18-19.

${ }^{76}$ Op. cit., p. 19.

${ }^{77}$ Ibid.

${ }^{78}$ Op. cit., p. 20.
} 
La admisión tácita por no contestación constituye prueba autosuficiente para establecer la verdad de los hechos afirmados por el demandante en su demanda, si no existe ninguna otra prueba que permita demostrar su verdad, debiéndose, eso sí, valorar junto con el resto de la prueba legalmente rendida en el proceso, en conformidad a las reglas de la sana crítica establecidas en el art. 456 del Código del Trabajo ${ }^{79}$.

Por tanto, si existe prueba contraria a la admisión tácita total, que tiene un mayor valor probatorio conforme a las reglas de la sana crítica, el juez deberá establecer los hechos controvertidos conforme a esta última prueba desechando la admisión tácita ${ }^{80}$.

\section{La admisión tácita como facultad del juez}

El art. $453 \mathrm{~N}^{\circ} 1$ inc. $7^{\circ}$ del Código del Trabajo al regular la admisión tácita por no contestación de la demanda, emplea la expresión verbal 'podrá'. Ahora bien, conforme a la regla de interpretación de la ley contenida en el art. 20 del Código Civil: "Las palabras de la ley se entenderá en su sentido natural y obvio [...]"; sentido natural y obvio que, se ha entendido, debe buscarse en el Diccionario de la lengua española de la Real Academia Española. Una de las acepciones de la palabra poder contenidas en ese 116 Diccionario es "Tener expedita la facultad o potencia de hacer algo", lo que revela que la admisión tácita constituye un poder, una facultad para el juez ${ }^{81}$, y no un deber u obligación procesal, quedando entregada su

${ }^{79}$ Flores con Delta Ingeniería y Construcción S.A. (2016).

${ }^{80}$ Debe advertirse que una jurisprudencia minoritaria dentro de la corriente jurisprudencial que sostiene que la admisión tácita por no contestación de la demanda constituye un antecedente probatorio para acreditar los hechos controvertidos, no estima necesario que el juez valore la prueba rendida en el proceso, bastando solamente tener en consideración la admisión tácita para establecer la veracidad de los hechos. En este sentido: Silva con Santibáñez (2016), Contreras con Agricotrans Ltda. (2016).

${ }^{81}$ Pizarro con Supermercados Cofrima S.A. (2008), Delgado con Riosal S.A. (2009), Cifuentes con Asesorías Fomento y Emprendimiento y otra (2012), González con Mena (2012), Barba con Ditzler Chile Limitada (2012), Urriola con Banco del Estado de Chile (2012), Lay con Agencia de Aduana Jorge Correa (2012), Pereira y otros con Pacific Chile S.A. y otras (2012), que concluye: "Tercero: Que, la disposición que se supone infringida por el Juez, emplea la expresión 'podrá', que no es otra cosa que un poder que se otorga al juez, para que con la libertad e independencia que le son propias, opte o no por ejercer una facultad. Cuarto: Que, frente a una norma cuyo tenor literal es claro, que no dispone imperativamente la conducta que un Juez debe seguir dadas determinadas circunstancias, sino que, por el contrario, le otorga una facultad para obrar de un modo excepcional, no cabe otorgarle el carácter de aplicación obligatoria por una interpretación que hace el recurrente, de determinados principios que informan el derecho laboral". En igual sentido: Aguirre con Sociedad de Servicios Médicos (2013), Peralta con Transportes Nazca Limitada y otra (2013), González con Figueroa (2013), Ogaz con PG Proyectos y 
utilización exclusivamente a la decisión del juez de la instancia, quien podrá utilizarla o no si concurren los presupuestos para su procedencia ${ }^{82}$. Conforme al texto del Código del Trabajo el juez puede o no ejercer tal facultad, constituyendo una potestad procesal facultativa ${ }^{83}$.

Al ser una facultad, el juez no debe señalar las razones por qué no aplica la admisión tácita sino la utiliza. De la misma forma puede proceder si recurre a la admisión tácita, debiendo, en este caso, solo velar porque concurran los supuestos fácticos que permiten su aplicación. Lo señalado es de la mayor importancia, puesto que si el juez decide no utilizar la admisión tácita para establecer la verdad de los hechos, no obstante que concurren los requisitos para su aplicación el demandante, no puede denunciar infracción de ley, infracción de la sana crítica ni vulneración de derecho fundamental a través del recurso de nulidad ${ }^{84}$, precisamente por el carácter facultativo que tiene para el juez, quedándole reservada en exclusiva su utilización ${ }^{85}$.

Prosegur Chile S.A. (2013), Campos y otro con Inmobiliaria Kunsa Ltda. y otra (2013), Rivera con Armijo (2014), Reyes con Transporte Sancott Ltda. (2014), Ferreira con Rojas (2014), Riquelme con Transportes Artisa Limitada (2014), Riquelme con Transporte de Pasajeros Álvaro Javier Becerra Jottar E.I.R.L. (2014), Servicios Generales Fullclean con Pulido (2015), Rollino con Constructora Ecisa Chile S.A. (2016), Maldonado con Fundición Quinta S.A. (2016), Siefeld con Well and Food (2016), Díaz con Arias (2016), Rugel con Bastias (2016), Gallardo con Transportes y Servicios Juan C (2016), Vega con Ingeniería y Desarrollo Isistem S.P.A. (2016), Sociedad Educacional INMA Ltda. con Vega (2016), Flores con Delta Ingeniería y Construcción S.A. (2016), Fuentes con Construmart S.A. (2016), Etura con Penta Vida Compañía de Seguros Vida S.A. (2016), Garrido con Díaz (2016), Cox con Vásquez (2016), Palma con Acoger Santiago Servicios Funerarios S.A. (2016), Cáceres con Álamo (2016).

${ }^{82}$ Carrasco (2010), p. 123, señala: "En cuanto a si dicha sanción es facultativa u obligatoria para el juez, consideramos que ella es facultativa porque la ley explícitamente dejó a criterio de éste determinar si los hechos expuestos por el actor se entenderán admitidos tácitamente en la sentencia definitiva. En efecto, el sentido de la ley parece claro al señalar -refiriéndose al juez en cuanto a los hechos que señala el demandante- que "podrá estimarlos como tácitamente admitidos". Por ello, de acuerdo con lo dispuesto en los arts. 19 y 23 del Código Civil, es decir, al tenor literal y el genuino sentido de la disposición consideramos que no cabe realizar otro tipo de interpretaciones sobre la norma"; FERNÁNDEZ (2011a), pp. 231-233.

${ }^{83}$ Bastidas con Multinegocios S.A. y otra (2010).

${ }^{84}$ Pereira y otros con Pacific Chile S.A. y otras (2012), Campos y otro con Inmobiliaria Kunsa Ltda. y otra (2013), Reyes con Transporte Sancott Ltda. (2014), Arredondo con Contardo (2014), Ferreira con Rojas (2014), Riquelme con Transporte de Pasajeros Álvaro Javier Becerra Jottar E.I.R.L. (2014), Servicios Generales Fullclean con Pulido (2015), Siefeld con Well and Food (2016), Maldonado con Fundición Quinta S.A. (2016), Vega con Ingeniería y Desarrollo Isistem S.P.A. (2016), Garrido con Díaz (2016).

${ }^{85}$ Fernández (2011), p. 232. 


\section{La admisión tácita como consecuencia del incumplimiento de una carga procesal por parte del demandado}

Nada dice el Código del Trabajo sobre cuál es la naturaleza jurídica que tiene la admisión tácita por no contestación de la demanda para el demandado. Por su parte, la jurisprudencia judicial ${ }^{86}$ y la doctrina nacional ${ }^{87}$, sin señalar fundamento jurídico, indican que la admisión tácita de los hechos es una "sanción" de relevancia probatoria para el demandado rebelde, no obstante sostener que la contestación es una carga procesal impuesta a este ${ }^{88}$.

En nuestra opinión, para determinar la naturaleza jurídica que tiene la admisión tácita de los hechos para el demandado rebelde, resulta esencial establecer previamente si la contestación de la demanda es una obligación o deber procesal o si, por el contrario, es una carga procesal; conceptos que la doctrina nacional ${ }^{89}$ y comparada ${ }^{90}$ han precisado y distinguido.

Ello porque si la contestación es un deber o una obligación procesal impuesta al demandado la admisión tácita constituirá una sanción para esta parte. En cambio, si es una carga procesal la admisión tácita es la consecuencia del incumplimiento de esa carga procesal, mas no una sanción.

En virtud del principio de buena fe procesal -reconocido expresamente como un principio de los procedimientos laborales en el art. 425 del Código del Trabajo- nuestro Código no solo purga los comportamientos contrarios a la buena fe si no que le impone a los intervinientes cargas y deberes delimitados por la legislación con el fin de hacer posible el cumplimiento tanto de los intereses públicos como privados que convergen en el juicio. Uno de estos deberes sería el de colaboración de las partes a fin que el proceso pueda cumplir su cometido, siendo una de las manifestaciones de dicho deber la contestación de demanda. El respeto de la buena fe haría que la contestación se erija como un deber procesal para el demandado ${ }^{91}$. De incumplirse el mismo el juez puede sancionarlo con

${ }^{86}$ Arancibia con Varas (2009), Fuentes con Francisco Gómez e Hijo Ltda. (2010), Águila con Invertec Pesquera Mar de Chiloé S.A. (2010), Urriola con Banco del Estado de Chile (2012), Lagos con Cortez y otro (2013), Gherardelli con Asesorías M y G Limitada y otra (2014), Allende con Saint Louis School Spa (2014), Riquelme con Transporte de Pasajeros Álvaro Javier Becerra Jottar E.I.R.L. (2014), Rollino con Constructora Ecisa Chile S.A. (2016), Páez con Exportadora e Importadora Turken S.A. (2016), Rivera con Sociedad Comercial Chungará SR (2016), SCM Lumina Copper con Inspección Provincial del Trabajo de Copiapó (2016), Flores con Delta Ingeniería y Construcción S.A. (2016).

${ }^{87}$ Carrasco (2010), pp. 123-124.

${ }^{88}$ Op. cit., p. 123.

${ }^{89}$ Colombo (1997) pp. 515-516; Carretta (2008), pp. 105-114.

${ }^{90}$ Couture (1958), pp. 209-210; Carneluti (1959), p. 65; Goldschmidt (1959), pp. 91-110, 126.

${ }^{91}$ Larroucau (2013), p. 289. 
la admisión tácita de los hechos afirmados por el actor, constituyendo la sanción del incumplimiento del deber de contestar.

Contrariamente a lo señalado, en nuestro proceso laboral se estableció la contestación de la demanda como una carga procesal para el demandado, estando establecido su cumplimiento en beneficio de esa parte, no en beneficio de la parte demandante ni del Estado. La contestación es uno de los instrumentos más importantes de que dispone el demandado para defender sus intereses en el proceso, puesto que a través de la misma podrá controvertir o admitir los hechos afirmados por el actor según lo estime conveniente, siendo, por lo mismo, libre de contestar o no hacerlo. Pero si no lo hace se pueden producir los efectos perjudiciales que contempla el Código del Trabajo, si el juez hace uso de la admisión tácita.

De esta forma, la admisión tácita no constituye una sanción procesal impuesta en perjuicio del demandado, sino que es una de las consecuencias posibles derivadas del incumplimiento de su carga procesal.

Las sanciones solo tienen lugar como consecuencia del incumplimiento de una obligación o deber procesal por parte del sujeto procesal a quien se le impuso, y la no contestación -que es el presupuesto esencial de aplicación de la admisión tácita- no constituye el incumplimiento de una obligación o deber procesal por parte del demandado, sino el incumplimiento de una carga procesal.

No resulta posible confundir dogmáticamente la sanción con las consecuencias del incumplimiento de una carga procesal, desde que el supuesto fáctico para la procedencia de ambas es distinto.

La sanción -según se indicó- es la consecuencia del incumplimiento de una obligación o deber procesal que el legislador establece en beneficio de un tercero distinto de aquel que debía cumplir con el mismo. Por ello, se impone una sanción porque con su incumplimiento ha resultado lesionado un interés de un tercero o, bien, no se ha satisfecho. En cambio, la carga procesal se establece en beneficio del mismo sujeto que debe cumplirla, por lo que su incumplimiento le perjudicará solo al mismo que debía cumplirla.

Refuerza que la admisión tácita de los hechos es la consecuencia del incumplimiento de una carga procesal el mismo art. $453 \mathrm{~N}^{\circ} 1$ inc. $7^{\circ}$ del Código del Trabajo, puesto que está concebida como una facultad del juez, que la puede o no ejercer, lo que está acorde con el hecho de que la contestación de demanda es una carga procesal.

Si se hubiera establecido como un deber procesal la contestación, la admisión tácita debió establecerse como un deber del juez, evento en el cual el juez tendría que tener por tácitamente admitidos los hechos afirmados en la demanda de no contestarse por el demandado. Al no consagrarse de ese modo, sino como facultad, confirma que la contesta- 
ción de demanda es una carga procesal y la admisión tácita una de las consecuencias posibles del incumplimiento de esa carga procesal que quedó entregada al criterio del juez.

Ahora bien, reconocemos que nuestra posición no es compartida por todos, desde que existe un sector de la doctrina que sostiene que las sanciones tienen lugar, también, en los casos de no cumplimiento de cargas procesales, siendo una de ellas la preclusión ${ }^{92}$, como lo sería la admisión tácita por no haberse contestado la demanda en tiempo y forma.

\section{REQUiSITOS DE LA SENTENCIA DEFINITIVA EN QUE SE HACE EFECTIVA LA ADMISIÓN TÁCITA}

Las opiniones contrapuestas que existen sobre los requisitos, efectos y naturaleza jurídica de la admisión tácita por no contestación se trasladan también al contenido de la sentencia definitiva que debe dictar el juez cuando utiliza la admisión tácita de los hechos para establecer la verdad de los hechos afirmados por el demandante por no contestación de la demanda. Opiniones contrapuestas a que contribuye el texto del inc. $7^{\circ}$ del $\mathrm{N}^{\circ} 1 \mathrm{del}$ art. 453 del Código del Trabajo, desde que el mismo solamente establece que 120 el juez puede hacer efectiva la admisión tácita en la sentencia definitiva, mas no indica los requisitos de la misma. De ahí que sea necesario determinar el contenido de la sentencia definitiva donde se utiliza la admisión tácita derivada de la no contestación de la demanda. Lo que es relevante, porque si no cumple la sentencia definitiva con las exigencias legales adolece de un defecto formal que la hace anulable en virtud de la causal de nulidad prevista en el art. 478 letra e) del Código del Trabajo $0^{93}$.

Si se estima que la admisión tácita en análisis corresponde hacerla efectiva antes de la recepción de la causa a prueba, por no existir hecho controvertido que acreditar, la sentencia definitiva no debe cumplir evidentemente con todos los requisitos establecidos en el art. 459 del Código del Trabajo ${ }^{94}$ (500 inc. final, tratándose de la sentencia definitiva dictada en el procedimiento monitorio). Ello porque tales requisitos solamente deben cumplirlos la sentencia definitiva dictada luego de concluido el procedimiento normal establecido por el Código del Trabajo, después de

${ }^{92}$ Colombo (1997), pp. 513-516.

${ }^{93} \mathrm{El}$ art. 478 letra c) del Código del Trabajo señala en lo pertinente: "El recurso de nulidad procederá, además: [...] c) Cuando la sentencia se hubiere dictado con omisión de cualquiera de los requisitos establecidos en los artículos 459, 495 o 501, inciso final, de este Código [...]".

${ }^{94}$ Aguirre con Sociedad de Servicios Médicos (2013), Bastías con Inversiones Tirúa S.A. (2013). 
recibida la causa a prueba y rendida la prueba ofrecida oportunamente por las partes. Tales requisitos deben cumplirlos las sentencias definitivas dictadas en la oportunidad prevista en los art. 457 y 500 del Código del Trabajo. De este modo, resulta evidente que aquella dictada conforme al art. $453 \mathrm{~N}^{\circ} 1$ inc. $7^{\circ}$ no debe cumplir con las exigencias contempladas en el $\mathrm{N}^{\circ} 4$ del art. 459 en relación con el art. 456 del Código del Trabajo, puesto que no existe prueba que apreciar al no haberse recibido la causa a prueba. Por tanto, la sentencia definitiva dictada en los procedimientos tramitados conforme a las reglas de aplicación general solamente debe cumplir con los requisitos de los números 1, 2, 3, 5, 6 y 7 del art. 459 del Código del Trabajo. Tratándose de la sentencia dictada en el procedimiento monitorio, debe cumplir con los requisitos de los números 1, 2, 5, 6 y 7 del art. 459 (art. 501 del Código del Trabajo), no analizando prueba alguna, por no haberse rendido. No lo dice expresamente ninguna norma legal, pero emana de la propia naturaleza de la admisión tácita total por no contestación de la demanda, que impide recibir la causa a prueba, no existiendo prueba que rendir y valorar en la sentencia definitiva que se dicte.

En cambio, si se estima que la admisión tácita constituye solamente una prueba o regla probatoria que puede utilizar el juez para acreditar los hechos sustanciales, pertinentes y controvertidos, no siendo un supuesto de exención de thema probandi, la sentencia definitiva debe cumplir con todas las exigencias establecidas en los arts. 459 y 500 del Código del Trabajo. Ello porque se debe recibir la causa a prueba, pudiendo las partes ofrecer y rendir prueba, que el juez deberá valorar en la sentencia definitiva. Por lo mismo, el juez deberá valorar la prueba rendida respetando las reglas de la sana crítica contempladas en el art. 456, mismas reglas a que debe sujetarse la admisión tácita, al ser un antecedente probatorio, según esta posición ${ }^{95}$.

\section{CONTROL DE LA ADMISIÓN TÁCITA MEDIANTE EL RECURSO DE NULIDAD}

El juez como ser humano que es, puede incurrir en errores al hacer uso de la admisión tácita por no contestación, siendo los mismos diversos. Así, por ejemplo, es posible que en la admisión tácita de los hechos afirmados en la demanda como consecuencia de la no contestación no se cumplan las exigencias legales, pero a pesar de ello el juez de la instancia haga uso de la misma, teniendo por tácitamente admitidos los hechos afirmados en el libelo. También puede suceder que, no obstante, concurrir los presupuestos (2016).

${ }^{95}$ Castro con Constructora Aysén Limitada (2016); González con Ingeaustral Limitada 
para aplicar la admisión tácita y ser aplicada, el juez le atribuya efectos distintos a los previstos por el Código del Trabajo, como puede ocurrir en caso de admitir tácitamente algunos hechos y otros no, a pesar de que la admisión tácita por no contestación de la demanda es total ${ }^{96}$, es decir, que si se ejerce deben admitirse todos los hechos afirmados, por ser indivisible la admisión tácita de los hechos.

Atendido que la admisión tácita se hace efectiva en la sentencia definitiva -sea que se dicte antes de recibir la causa a prueba por estimarse no necesaria o luego de concluida la etapa probatoria- el único medio de impugnación de que dispone la parte agraviada es el recurso de nulidad ${ }^{97}$. Ahora bien, lo que corresponde determinar es el motivo de nulidad que debe invocar la parte agraviada (el demandado) al interponer el recurso de nulidad. Cuestión de la mayor importancia, porque al ser el recurso de nulidad un medio de impugnación de derecho estricto y existir más de un motivo de nulidad posible de invocar, es carga del recurrente invocar el motivo de nulidad específico establecido por el legislador para denunciar el vicio cometido en la sentencia definitiva impugnada, debiendo existir corresponde entre el vicio denunciado y la causal de nulidad invocada ${ }^{98}$.

La causal de nulidad depende del vicio cometido por el juez, debiéndose invocar, eso sí, en la mayoría de los casos la establecida en el art. 477 inc. $1^{\circ}$ del Código del Trabajo, que admite la procedencia del recurso de nulidad cuando:

“en la tramitación del procedimiento o en la dictación de la sentencia definitiva se hubieren infringido sustancialmente derechos o garantías constitucionales".

Ello porque es la que más comúnmente se configura cuando no se observan los requisitos de procedencia de la admisión tácita. Concretamente se vulnera la garantía del debido proceso establecida en el art. $19 \mathrm{~N}^{\circ} 3$ inc. $5^{\circ}$ de la Constitución Política, desde que se infringe una regla procesal establecida por el legislador, no observándose por el juez las exigencias legales del procedimiento.

${ }^{96}$ Arévalo con Labrador Ltda. (2011): "no permite que el sentenciador distinga entre los hechos alegados por el actor, cuáles tiene por tácitamente admitidos y cuáles no, ya que el legislador no realiza distinción alguna y no existen otros elementos en la causa que sirvan de fundamento para hacer algún distingo". En igual sentido: Flores con Luisa Angélica Rojas Cortés E.I.R.L. y otros (2013).

${ }^{97} \mathrm{El}$ art. 477 inc. $1^{\circ}$ del Código del Trabajo dispone: "Tratándose de las sentencias definitiva sólo será procedente el recurso de nulidad [...]".

${ }^{98}$ Lanata (2011), pp. 138-139; Mella y Domínguez (2011), pp. 154-165; Astudillo (2012), pp. 17-20. 
De esta forma, el recurrente deberá invocar necesariamente como normas sustentadoras de su recurso de nulidad los arts. $453 \mathrm{~N}^{\circ} 1$ inc. $7^{\circ}$ y 477 inc. $1^{\circ}$ del Código del Trabajo, además, del art. $19 \mathrm{~N}^{\circ} 3$ inc. $5^{\circ}$ de la Constitución Política.

Las cortes de apelaciones de nuestro país han acogido recursos de nulidad cuando se ha aplicado indebidamente la admisión por no contestación de la demanda fundado en la infracción de la garantía del debido proceso. Los principales vicios que han motivado a acoger el recurso de nulidad son:

i) no concurrencia de los presupuestos fácticos para utilizar la facultad judicial del art. $453 \mathrm{~N}^{\circ} 1$ inc. $7^{\circ}$ del Código del Trabajo $0^{99}$;

ii) utilización de la misma en una oportunidad procesal distinta a la establecida por el Código del Trabajo ${ }^{100}$;

iii) aplicación de la admisión tácita en circunstancias que debió recibirse la causa a prueba, porque a pesar de concurrir sus presupuestos de aplicación los hechos afirmados en la demanda son distintos a los indicados en sus documentos fundantes ${ }^{101}$;

iv) atribución de efectos distintos a los legales, al admitirse solamente algunos hechos afirmados en la demanda y otros tenerlos por no $\operatorname{ciertos}^{102} \mathrm{y}$

v) acogerse pretensiones que no guardan relación con los hechos $\operatorname{admitidos}^{103}$.

\section{REFLEXIONES FINALES}

A pesar de las discusiones existentes en la doctrina y jurisprudencia, lo cierto es que predomina en nuestro proceso laboral la opinión de ser la admisión tácita por falta de contestación un supuesto de relevo de prueba de los hechos admitidos, detentando estos la calidad de pacíficos por no

${ }^{99}$ Fuentes con Francisco Gómez e Hijo Ltda. (2010), Águila con Invertec Pesquera Mar de Chiloé S.A. (2010), Sindicato Empresa Tamegal S.A. con Tamegal S.A. (2013), Riquelme con Transportes Artisa Limitada (2014); Navarrete con MM Construcciones E.I.R.L. (2014), Gherardelli con Asesorías M y G Limitada y otra (2014), Allende con Saint Louis School Spa (2014), Ramos con Sepúlveda (2014), SCM Lumina Copper con Inspección Provincial del Trabajo de Copiapó (2016).

${ }^{100}$ Urriola con Banco del Estado de Chile (2012), Lay con Agencia de Aduana Jorge Correa (2012), Hernández con Sociedad Agrícola Alborada S.A. (2014), Navarro con Verdugo (2014), Llano con Prosegur Ltda. (2014).

${ }^{101}$ Bastías con Inversiones Tirúa S.A. (2013), Flores con Delta Ingeniería y Construcción S.A. (2016), Cabello con Servicios Industriales Integra Limitada (2016).

${ }^{102}$ Arévalo con Labrador Ltda. (2011), Flores con Luisa Angélica Rojas Cortés E.I.R.L. y otros (2013).

${ }^{103}$ Aguirre con Sociedad de Servicios Médicos (2013). 
haber sido controvertidos, no teniendo el demandante la necesidad de acreditarlos. La admisión en cuestión permite al juez tener como hechos pacíficos aquellos afirmados en la demanda, evitando la recepción de la causa a prueba al no haberse controvertido hecho alguno por el demandado, siendo innecesaria esta etapa procesal. Es por ello que se ha erigido en una herramienta que permite hacer eficaz en los procedimientos laborales los principios de celeridad y economía procesal consagrados expresamente en el art. 425 del Código del Trabajo, evitando toda la etapa probatoria innecesaria. Se trata de una facultad del juez que tiene como supuesto de ejercicio el incumplimiento de una carga procesal del demandado.

Si bien la admisión tácita constituye un instrumento que permite al actor -que generalmente es la parte trabajadora- obtener una tutela judicial más rápida, la misma debe ser utilizada prudencialmente por el juez, que es a quien el Código del Trabajo ha encomendado su ejercicio con carácter facultativo. Esto porque se tienen por establecidos los hechos fundantes de las pretensiones del demandante únicamente sobre la base del comportamiento omisivo tenido por el demandado en el proceso, al cual el Código del Trabajo le atribuye efectos sobre los hechos allegados al proceso por el actor.

Sin embargo, la realidad de las cosas es que no existe ninguna eviden124 cia que permita al juez establecer la verdad de los hechos; situación que provoca la incertidumbre de saber si los enunciados fácticos afirmados por el demandante son verdaderos o falsos, existiendo el riesgo que la decisión judicial sea fundada sobre un enunciado fáctico falso, pudiéndose condenar al demandado cuando en realidad no correspondía, por no ser cierta la causa de pedir que funda la pretensión del demandante ${ }^{104}$. Riesgo que puede afectar la calidad de las decisiones judiciales y el ejercicio de la jurisdicción, la cual busca otorgar la tutela judicial a quien realmente corresponde, además, de perseguir reestablecer el Derecho cuando ha sido conculcado.

A lo anterior hay que agregar que la admisión tácita puede involucrar un fraude procesal cuando los hechos que permite tener por pacíficos no han sucedido de esa forma; anormalidad procesal que el juez no solo debe evitar sino, también, sancionar (art. 428 del Código del Trabajo).

Asimismo, si los hechos expuestos en la demanda son absurdos, no tienen relación con la realidad o las peticiones del actor son desproporcionadas, el juez no debería recurrir a la admisión tácita, desde que puede provocar un resultado absurdo e injusto, lo cual repugna al Derecho ${ }^{105}$.

${ }^{104}$ Para un estudio más detallado sobre los riesgos que conlleva concebir la admisión tácita por no contestación de la demanda como un supuesto de exención de recepción de la causa a prueba, véase TARUfFo (2008), pp. 137-151; TARUFFO (2010), pp. 140-153.

${ }^{105}$ Carrasco (2010), p. 124. 
En estos casos, no obstante que concurren los requisitos procesales para utilizar la admisión tácita, el juez debe recibir la causa a prueba y ordenar que el demandado pruebe los hechos que constituyen la causa de pedir de sus pretensiones, por exigirlo el valor justicia ${ }^{106}$. La facultad que la legislación laboral confiere al juzgador de manera alguna permite dictar resoluciones injustificadas, faltas de fundamento y contrarias a la realidad, debiendo ser utilizada de manera ponderada y razonable, sin que puedan darse por establecidos hechos que resultan contradictorios o a cuyo respecto no baste la aceptación del demandado para tenerlos por acreditados ${ }^{107}$.

Atendida las ventajas y riesgos que presenta la admisión de hechos, el juez debe realizar un ejercicio prudencial de la misma, evitando un uso que conduzca a establecer hechos que no se condicen con la realidad. Si existen dudas sobre la veracidad de los hechos afirmados por el demandante de acuerdo con los antecedentes del proceso, resulta más acertado recibir la causa a prueba sin hacer uso de la admisión tácita. Decisión que otorga la posibilidad a las partes de ofrecer y rendir prueba que permita acreditar la veracidad de los hechos, disminuyendo el riesgo de resolver sobre la base de hechos falsos.

En suma, la admisión tácita constituye una facultad que debe ser ejercida racionalmente de acuerdo con el mérito del proceso y teniendo en cuenta los principios generales que informa el procedimiento laboral, en especial la buena fe de las partes ${ }^{108}$, evitando ser utilizada frente a hechos que constituyen un atentado evidente de la realidad.

\section{Bibliografía CITADA}

ArÁnguiz ZúÑiga, Tita (2011). "Hechos tácitamente aceptados en la audiencia preparatoria". Revista Laboral Chilena. $\mathrm{N}^{\circ}$ 1. Santiago. Enero.

Astudillo Contreras, Omar (2012). El recurso de nulidad laboral. Algunas consideraciones técnicas. Santiago: AbeledoPerrot-LegalPublishing Chile.

BACHMAIER Winter, Lorena (1994). La rebeldía en el proceso civil norteamericano y español. Madrid: Editorial Universidad Complutense.

Barrientos Zamorano, Marcelo (2012): "La obligación de seguridad en la subcontratación laboral: previsibilidad del hecho y del daño". Revista Chilena de Derecho, Vol. 38. $\mathrm{N}^{\circ}$ 1. Santiago.

${ }^{106}$ Carrasco (2010), p. 125.

${ }^{107}$ Aguirre con Sociedad de Servicios Médicos (2013); Bastías con Inversiones Tirúa S.A. (2013); Flores con Delta Ingeniería y Construcción S.A. (2016).

${ }^{108}$ Martínez con Corporación Nacional Forestal (2010). 
Carrasco Poblete, Jaime (2009): "La rebeldía en el Anteproyecto de Código Procesal Civil". Cuadernos de Extensión Jurídica, $\mathrm{N}^{\circ} 16$. Santiago.

Carrasco Poblete, Jaime (2010). La rebeldía en los procesos civily laboral. Santiago: AbeledoPerrot-LegalPublishing.

CARneluti, Francesco (1959). Instituciones del proceso civil. Buenos Aires: EJEA. Vol. I.

Carretta Muñoz, Francesco (2008). "Deberes procesales de las partes en el proceso civil chileno: referencia a la buena fe procesal y al deber de coherencia". Revista de Derecho de la Universidad Austral, vol. xxı, N 1 . Valdivia.

Colombo Campbell, Juan (1997). Los actos procesales. Santiago: Editorial Jurídica de Chile.

Couture, Eduardo (1958). Fundamentos del derecho procesal civil. Buenos Aires: Depalma.

Cruces Neira, Jaime Álvaro (2015): "La vigencia del principio dispositivo, el deber de congruencia y los límites en la determinación judicial de medidas de reparación en el procedimiento de tutela laboral", en Diego PALOMO VÉLEZ (dir.), Proceso y justicia laboral: lecturas a contracorriente. Santiago: Ediciones Jurídicas Santiago.

Dávila Millán, María Encarnación (1997). Litisconsorcio necesario: concepto y tratamiento procesal. Tercera edición. Barcelona: Editorial Bosch.

De La Oliva Santos, Andrés; Fernández, Miguel Ángel (1995): Derecho procesal 126 civil. Cuarta edición. Madrid: Editorial Centro de Estudios Ramón Areces S.A. Tomo II.

Delgado Castro, Jordi (2014). "La inversión de los efectos del silencio: "quien calla sí otorga". Revista de Derecho de la Pontificia Universidad Católica de Valparaíso. Vol. XLII. Valparaíso.

Devis Hechandía, Hernando (1972). Teoría general de la prueba judicial. Buenos Aires: Editorial Víctor P. de Zavalía-Editor Alberti. Tomo I.

Díaz MÉndez, Marcela Mabel (2012). "El artículo $453 \mathrm{~N}^{\circ} 1$ inciso $7^{\circ}$ del Código del Trabajo, cuna facultad del juzgador?”. Revista Laboral Chilena. $\mathrm{N}^{\circ}$ 7. Santiago.Julio.

Diez Schwerter, José Luis (2008). "Responsabilidad civil derivada de accidentes del trabajo y enfermedades profesionales: aspectos relevantes de su regulación y operatoria actual". Revista de Derecho de la Pontificia Universidad Católica de Valparaíso, Vol. Xxxi. Valparaíso.

FAROLFI, Alessandro (2015). Il principio di non contestazione nel processo civile. Milano: Giuffré Editore.

FERnÁndez Toledo, Raúl (2011a). Las facultades y deberes del juez en materia probatoria en el proceso laboral. Análisis crítico. Santiago: Thomson Reuters-Punto Lex.

Fernández Toledo, Raúl (2011b): "Principios Dispositivo y de Aportación de Parte. Su incidencia en la Iniciativa Probatoria del Juez". Revista Chilena de Derecho del Trabajo y de la Seguridad Social, Vol. 2, N 3. Santiago.

Goldschmidt, James (1961). Principios generales del proceso, I: teoría general del proceso. Buenos Aires: EJEA. 
Lanata Fuenzalida, Gabriela (2011). El sistema de recursos en el proceso laboral chileno. Segunda edición. Santiago: Abeledo Perrot-LegalPublishing Chile.

Larroucau Torres, Jorge (2013). "Tres lecturas de la Buena fe procesal". Revista Chilena de Derecho Privado, N ${ }^{\circ}$ 21. Santiago.

Lessona, Carlos (1928). Teoría general de la prueba en el derecho civil. Madrid: Editorial Reus. Tomo I.

Mella Cabrera, Patricio, Álvaro Domínguez Montoya (2011). "El recurso de nulidad laboral”. Revista de Derecho Universidad de Concepción. Año Lxxıx. N 229230. Concepción.

Montero Aroca, Juan (2006). La prueba en el proceso civil. Sexta edición. Madrid: Civitas S.A.

Muñoz Sabaté, Lluis (2001). Fundamentos de prueba judicial civil. L.E.C. 1/2000. Barcelona: J.M. Bosch.

Orellana Torres, Fernando, Álvaro Pérez Ragone (2007). "Radiografía de la rebeldía en el proceso civil: tópicos hacia una adecuada regulación en la nueva justicia civil". Ius et Praxis. Año 13. $\mathrm{N}^{\circ}$ 2. Talca.

Ortells Ramos, Manuel (2007). Derecho procesal civil. Séptima edición. Pamplona: Editorial Thomson-Aranzadi.

Palavecino Cáceres, Claudio (2010a). "Efecto jurídico de la no contestación de la demanda ante la nueva jurisdicción laboral". Actualidad Laboral, $\mathrm{N}^{\circ} \mathrm{LXXXV}$. Caracas.

Palavecino Cáceres, Claudio (2010b). "La responsabilidad solidaria en la subcontratación laboral. Algunas consideraciones sobre su naturaleza y sus efectos". Revista Chilena de Derecho del Trabajo y de la Seguridad Social, Vol. 1, N 1 . Santiago.

Palavecino CÁceres, Claudio (2011a): "El retorno del inquisidor: Las potestades judiciales en materia probatoria en el procedimiento laboral chileno". Revista Latinoamericana de Derecho Social, $\mathrm{N}^{\circ}$ 13. Ciudad de México.

Palavecino Cáceres, Claudio (2011b). "Subcontratación: Necesidad de provocar litisconsorcio pasivo con el empleador para demandar a terceros responsables. Comentario a la sentencia de la Excma. Corte Suprema, Rol No 3198-2010”. Revista de Derecho Escuela de Postgrado, $\mathrm{N}^{\circ} 1$. Santiago.

Romero Seguel, Alejandro (1998). "El litisconsorcio necesario en el Derecho Procesal chileno. Doctrina y jurisprudencia". Revista Chilena de Derecho, vol. xxv, $\mathrm{N}^{\circ}$ 2. Santiago.

SAPONe, Natalino (2012). Il principio di non contestazione nel processo del lavoro. Milano: Giuffré Editore.

Silva Álvarez, Óscar (2009). "Sobre la ficta confessio en materia procesal laboral: algunos comentarios a partir de la actual tendencia jurisprudencial”. Nomos - Universidad de Viña del Mar, $\mathrm{N}^{\circ}$ 4. Viña del Mar.

TARuffo, Michele (2008). “¿Verdad negociada?”. Revista de Derecho Universidad Austral de Chile. vol. XXI. $\mathrm{N}^{\circ} 1$. Valdivia.

TARUfFo, Michele (2010). Simplemente la verdad. El juez y la construcción de los hechos. Madrid: Marcial Pons. 
Zepeda Pinto, Miguel (2013). "De la rebeldía y sus efectos en el procedimiento laboral de aplicación general". Revista Chilena de Derecho del Trabajo y de la Seguridad Social. Vol. 4. N ${ }^{\circ}$ 7. Santiago.

\section{Jurisprudencia citada}

Cortes de Apelaciones de Chile

Año 2008

Pizarro con Supermercados Cofrima S.A. (2008): Corte de Apelaciones de Punta Arenas, 13 de septiembre de 2008, Base Jurisprudencial del Poder Judicial (recurso de nulidad, rol Reforma Laboral No 9-2008).

Año 2009

Arancibia con Varas (2009): Corte de Apelaciones de la Serena, 17 de septiembre de 2009, Base Jurisprudencial del Poder Judicial (recurso de nulidad, rol Reforma Laboral No 102-2009).

Delgado con Riosal S.A. (2009): Corte de Apelaciones de Valparaíso, 23 de septiembre de 2009, Base Jurisprudencial del Poder Judicial (recurso de nulidad, rol Reforma Laboral No $345-2009$ ).

Año 2010

Águila con Invertec Pesquera Mar de Chiloé S.A. (2010): Corte de Apelaciones de

Puerto Montt, 30 de agosto de 2010, Base Jurisprudencial del Poder Judicial (recurso de nulidad, rol Reforma Laboral N 133-2010).

Bastidas con Multinegocios S.A. y otra (2010): Corte de Apelaciones de La Serena, 30 de julio de 2010, Base Jurisprudencial del Poder Judicial (recurso de nulidad, Rol Reforma Laboral N 54-2010.

Fuentes con Francisco Gómez e Hijo Ltda. (2010): Corte de Apelaciones de Valparaíso, 11 de enero de 2010, Base Jurisprudencial del Poder Judicial (recurso de nulidad, rol Reforma Laboral $\mathrm{N}^{\circ}$ 500-2009).

Martínez con Corporación Nacional Forestal (2010): Corte de Apelaciones de Temuco, 17 de marzo de 2010, Base Jurisprudencial del Poder Judicial (recurso de nulidad, Rol Reforma Laboral N 3-2010).

Año 2011

Arévalo con Labrador Ltda. (2011): Corte de Apelaciones de Santiago, 28 de noviembre de 2011, Base Jurisprudencial del Poder Judicial (recurso de nulidad, rol Reforma Laboral N ${ }^{\circ}$ 273-2011).

Año 2012

Barba con Ditzler Chile Limitada (2012): Corte de Apelaciones de Santiago, 8 de junio de 2012, Base Jurisprudencial del Poder Judicial (recurso de nulidad, rol Reforma Laboral N 1280-2011).

Cifuentes con Asesorías Fomento y Emprendimiento y otra (2012): Corte de Apelaciones de Santiago, 22 de mayo de 2012, Base Jurisprudencial del Poder Judicial (recurso de nulidad, rol Reforma Laboral N 1668-2011). 
Espinoza y otro con Decorados Industriales S.A. (2012): Corte de Apelaciones de Santiago, 12 de noviembre de 2012, Base Jurisprudencial del Poder Judicial (recurso de nulidad, rol Reforma Laboral N 919-2012).

González con Mena (2012): Corte de Apelaciones de Santiago, 7 de junio de 2012, Base Jurisprudencial del Poder Judicial (recurso de nulidad, rol Reforma Laboral $\left.\mathrm{N}^{\circ} 1619-2011\right)$.

Lay con Agencia de Aduana Jorge Correa (2012): Corte de Apelaciones de Valparaíso, 17 de octubre de 2012, Base Jurisprudencial del Poder Judicial (recurso de nulidad, rol Reforma Laboral $\mathrm{N}^{\circ}$ 290-2012).

Pereira y otros con Pacific Chile S.A. y otras (2012): Corte de Apelaciones de Santiago, 18 de diciembre de 2012, Base Jurisprudencial del Poder Judicial (recurso de nulidad, rol Reforma Laboral $\mathrm{N}^{\circ}$ 1451-2012).

Rezzio con Ilustre Municipalidad de Santiago (2012): Corte de Apelaciones de Santiago, 20 de agosto de 2012, Base Jurisprudencial del Poder Judicial (recurso de nulidad, rol Reforma Laboral N 433-2012).

Urriola con Banco del Estado de Chile (2012): Corte de Apelaciones de Santiago, 22 de junio de 2012, Base Jurisprudencial del Poder Judicial (recurso de nulidad, rol Reforma Laboral $N^{\circ} 1842-2011$ ).

Año 2013

Aguirre con Sociedad de Servicios Médicos (2013): Corte de Apelaciones de Concepción, 19 de febrero de 2013, Base Jurisprudencial del Poder Judicial (recurso de nulidad, rol Reforma Laboral N 320-2012).

Alarcón con Inversiones Colina S.A. (2013): Corte de Apelaciones de Santiago, 4 de noviembre de 2013, Base Jurisprudencial del Poder Judicial (recurso nulidad, rol Reforma Laboral $\left.\mathrm{N}^{\circ} 1000-2013\right)$.

Bastías con Inversiones Tirúa S.A. (2013): Corte de Apelaciones de Concepción, 27 de febrero de 2013, Base Jurisprudencial del Poder Judicial (recurso de nulidad, rol Reforma Laboral $\mathrm{N}^{\circ} 323-2012$ ).

Bustamante con Servicios Integrales C y C Ltda. (2013): Corte de Apelaciones de Santiago, 25 de noviembre de 2013, Base Jurisprudencial del Poder Judicial (recurso de nulidad, rol Reforma Laboral $N^{\circ} 1137-2013$ ).

Campos y otro con Inmobiliaria Kunsa Ltda. y otra (2013): Corte de Apelaciones de Temuco, 12 de noviembre de 2013, Base Jurisprudencial del Poder Judicial (recurso de nulidad, rol Reforma Laboral N²07-2013).

Compañía Minera Doña Inés de Collahuasi SCM con Inspección Provincial del Trabajo de Iquique (2013): Corte de Apelaciones de Iquique, 2 de enero de 2013, Base Jurisprudencial del Poder Judicial (recurso de nulidad, rol Reforma Laboral No 89-2012).

Flores con Luisa Angélica Rojas Cortés E.I.R.L. y otros (2013): Corte de Apelaciones de La Serena, 13 de diciembre de 2013, Base Jurisprudencial del Poder Judicial (recurso de nulidad, rol Reforma Laboral No 135-2013).

G4S Security Services Regiones con Inspección Provincial del Trabajo de Antofagasta (2013): Corte de Apelaciones de Antofagasta, 6 de diciembre de 
2013, Base Jurisprudencial del Poder Judicial (recurso de nulidad, rol Reforma Laboral N 144-2013).

González con Figueroa (2013): Corte de Apelaciones de Puerto Montt, 27 de mayo de 2013, Base Jurisprudencial del Poder Judicial (recurso de nulidad, rol Reforma Laboral N 44-2013).

Lagos con Cortez y otro (2013): Corte de Apelaciones de Valparaíso, 7 de marzo de 2013, Base Jurisprudencial del Poder Judicial (recurso de nulidad, rol Reforma Laboral $\mathrm{N}^{\circ}$ 25-2013).

Mamani con Ilustre Municipalidad de Camiña (2013): Corte de Apelaciones de Iquique, 27 de junio de 2013, Base Jurisprudencial del Poder Judicial (recurso de nulidad, rol Reforma Laboral N²6-2013).

Montero con Ingeproc Ltda. (2013): Corte de Apelaciones de Santiago, 6 de diciembre de 2013, Base Jurisprudencial del Poder Judicial (recurso de nulidad, rol Reforma Laboral N 1054-2013).

Ogaz con PG Proyectos y Prosegur Chile S.A. (2013): Corte de Apelaciones de Santiago, 6 de noviembre de 2013, Base Jurisprudencial del Poder Judicial (recurso de nulidad, rol Reforma Laboral N 818-2013).

Peralta con Transportes Nazca Limitada y otra (2013): Corte de Apelaciones de Antofagasta, 3 de abril de 2013, Base Jurisprudencial del Poder Judicial (recurso de nulidad, rol Reforma Laboral No 29-2013).

Sindicato Empresa Tamegal S.A. con Tamegal S.A. (2013): Corte de Apelaciones de Santiago, 12 de agosto de 2013, Base Jurisprudencial del Poder Judicial (recurso de nulidad, rol Reforma Laboral $\mathrm{N}^{\circ}$ 735-2013).

Ulloa con Rolke (2013): Corte de Apelaciones de Santiago, 3 de octubre de 2013, Base Jurisprudencial del Poder Judicial (recurso de nulidad, rol Reforma Laboral N 651-2013).

Año 2014

Águila con Empresa Trancura Ingeniería y Construcción Limitada (2014): Corte de Apelaciones de Santiago, 24 de septiembre de 2014, Base Jurisprudencial del Poder Judicial (recurso de nulidad, rol Reforma Laboral N 568-2014).

Allende con Saint Louis School Spa (2014): Corte de Apelaciones de Santiago, 20 de noviembre de 2014, Base Jurisprudencial del Poder Judicial (recurso de nulidad, rol Reforma Laboral N 576-2014).

Arredondo con Contardo (2014): Corte de Apelaciones de Valparaíso, 28 de agosto de 2014, Base Jurisprudencial del Poder Judicial (recurso de nulidad, rol Reforma Laboral $\mathrm{N}^{\circ} 328-2014$ ).

Cevallos con MUT Gestión Móvil S.A. (2014): Corte de Apelaciones de Santiago, 11 de noviembre de 2014, Base Jurisprudencial del Poder Judicial (recurso de nulidad, rol Reforma Laboral $\left.N^{\circ} 823-2014\right)$.

Contreras con Monras y Gunther Ltda. (2014): Corte de Apelaciones de Santiago, 28 de julio de 2014, Base Jurisprudencial del Poder Judicial (recurso de nulidad, rol Reforma Laboral $N^{\circ} 169-2014$ ). 
Ferreira con Rojas (2014): Corte de Apelaciones de La Serena, 7 de octubre de 2014, Base Jurisprudencial del Poder Judicial (recurso de nulidad, rol Reforma Laboral $\mathrm{N}^{\circ}$ 91-2014).

Gherardelli con Asesorías M y G Limitada y otra (2014): Corte de Apelaciones de Santiago, 12 de noviembre de 2014, Base Jurisprudencial del Poder Judicial (recurso de nulidad, rol Reforma Laboral N 958-2014).

González con Comercial Berta Fernández Limitada (2014): Corte de Apelaciones de San Miguel, 30 de octubre de 2014, Base Jurisprudencial del Poder Judicial (recurso de nulidad, rol Reforma Laboral N²84-2014).

González con Sociedad Agro Ganadera Forestal y Frutícola Buena Vista Ltda. (2014): Corte de Apelaciones de Chillán, 23 de diciembre de 2014, Base Jurisprudencial del Poder Judicial (recurso de nulidad, rol Reforma Laboral $N^{\circ}$ 94-2014).

Hernández con Sociedad Agrícola Alborada S.A. (2014): Corte de Apelaciones de Talca, 17 de septiembre de 2014, Base Jurisprudencial del Poder Judicial (recurso de nulidad, rol Reforma Laboral N 154-2014).

Llano con Prosegur Ltda. (2014): Corte de Apelaciones de Santiago, 27 de noviembre de 2014, Base Jurisprudencial del Poder Judicial (recurso de nulidad, rol Reforma Laboral $\mathrm{N}^{\circ}$ 916-2014).

Navarrete con MM Construcciones E.I.R.L. (2014): Corte de Apelaciones de Valparaíso, 27 de octubre de 2014, Base Jurisprudencial del Poder Judicial (recurso de nulidad, rol Reforma Laboral N ${ }^{\circ} 395-2014$ ).

Navarro con Verdugo (2014): Corte de Apelaciones de Talca, 10 de noviembre de 2014, Base Jurisprudencial del Poder Judicial (recurso de nulidad, rol Reforma Laboral No 172-2014).

Ramos con Sepúlveda (2014): Corte de Apelaciones de Valparaíso, 24 de diciembre de 2014, Base Jurisprudencial del Poder Judicial (recurso de nulidad, rol Reforma Laboral N 471-2014).

Reyes con Transporte Sancott Ltda. (2014): Corte de Apelaciones de Santiago, 13 de mayo de 2014, Base Jurisprudencial del Poder Judicial (recurso de nulidad, rol Reforma Laboral N 1822-2013).

Riquelme con Transportes Artisa Limitada (2014): Corte de Apelaciones de Santiago, 21 de octubre de 2014, Base Jurisprudencial del Poder Judicial (recurso de nulidad, rol Reforma Laboral N 849-2014).

Riquelme con Transporte de Pasajeros Álvaro Javier Becerra Jottar E.I.R.L. (2014): Corte de Apelaciones de Punta Arenas, 12 de diciembre de 2014, Base Jurisprudencial del Poder Judicial (recurso de nulidad, rol Reforma Laboral $N^{\circ} 47-2014$ ).

Rivera con Armijo (2014): Corte de Apelaciones de Talca, 3 de abril de 2014, Base Jurisprudencial del Poder Judicial (recurso de nulidad, rol Reforma Laboral $\left.\mathrm{N}^{\circ} 38-2014\right)$.

Año 2015

Aranda y otros con Comercial Liquiplast Ltda. y otras (2015): Corte de Apelaciones de Talca, 2 de enero de 2015, Base Jurisprudencial del Poder Judicial (recurso de nulidad, rol Reforma Laboral N²28-2014). 
Arteaga con Transportes Carlos Abarca Limitada (2015): Corte de Apelaciones de San Miguel, 13 de febrero de 2015, Base Jurisprudencial del Poder Judicial (recurso de nulidad, rol Reforma Laboral No 2-2015).

Concha con Salazar (2015): Corte de Apelaciones de La Serena, 15 de septiembre de 2015, Base Jurisprudencial del Poder Judicial (recurso de nulidad, rol Reforma Laboral N 111-2015).

Contreras con Inversiones Flores y Cortés Limitada (2015): Corte de Apelaciones de La Serena, 28 de agosto de 2015, Base Jurisprudencial del Poder Judicial (recurso de nulidad, rol Reforma Laboral $\mathrm{N}^{\circ}$ 106-2015).

Contreras con Makluf (2015): Corte de Apelaciones de Valparaíso, 16 de abril de 2015, Base Jurisprudencial del Poder Judicial (recurso de nulidad, rol Reforma Laboral N 86-2015).

Donaire y otros con Administradora de Supermercado (2015): Corte de Apelaciones de Santiago, 6 de marzo de 2015, Base Jurisprudencial del Poder Judicial (recurso de nulidad, rol Reforma Laboral $\mathrm{N}^{\circ}$ 1313-2014).

Ludueña con Aguirre (2015): Corte de Apelaciones de Rancagua, 5 de enero de 2015, Base Jurisprudencial del Poder Judicial (recurso de nulidad, rol Reforma Laboral $\left.N^{\circ} 130-2014\right)$.

Martínez con Genco S.A. (2015): Corte de Apelaciones de Santiago, 24 de agosto de 2015, Base Jurisprudencial del Poder Judicial (recurso de nulidad, rol Reforma Laboral 840-2015).

132 Montaño con Human Resources II S.A. (2015): Corte de Apelaciones de Antofagasta, 8 de mayo de 2015, Base Jurisprudencial del Poder Judicial (recurso de nulidad, rol Reforma Laboral N ${ }^{\circ}$ 53-2015).

Moreno con Soldaduras y Estructuras Lucero y Rivera Ltda. y otra (2015): Corte de Apelaciones de Santiago, 10 de agosto de 2015, Base Jurisprudencial del Poder Judicial (recurso de nulidad, rol Reforma Laboral N 605-2015).

Orellana con Constructora Antártida Ltda. y otra (2015): Corte de Apelaciones de Santiago, 26 de junio de 2015, Base Jurisprudencial del Poder Judicial (recurso de nulidad, rol Reforma Laboral N 408-2015).

Servicios Generales Fullclean con Pulido (2015): Corte de Apelaciones de Santiago, 25 de marzo de 2015, Base Jurisprudencial del Poder Judicial (recurso de nulidad, rol Reforma Laboral N 1886-2014).

Vargas con Construcciones Luis Antonio Pinochet Vera y otra (2016): Corte de Apelaciones de Santiago, 26 de agosto de 2015, Base Jurisprudencial del Poder Judicial (recurso nulidad, rol Reforma Laboral N $540-2015$ ).

Año 2016

Bianchi con Ilustre Municipalidad de Iquique (2016): Corte de Apelaciones de Iquique, 12 de diciembre de 2016, Base Jurisprudencial del Poder Judicial (recurso de nulidad, rol Reforma Laboral $N^{\circ}$ 95-2016).

Bustamante con Fernández (2016); Corte de Apelaciones de Valparaíso, 25 de enero de 2016, Base Jurisprudencial del Poder Judicial (recurso de nulidad, rol Reforma Laboral N 6-2016). 
Cabello con Servicios Industriales Integra Limitada (2016): Corte de Apelaciones de Santiago, 24 de junio de 2016, Base Jurisprudencial del Poder Judicial (recurso de nulidad, rol Reforma Laboral N 403-2016).

Cáceres con Álamo (2016): Corte de Apelaciones de Valparaíso, 2 de noviembre de 2016, Base Jurisprudencial del Poder Judicial (recurso de nulidad, rol Reforma Laboral N 487-2016).

Calderón con Condominio Los Veleros (2016): Corte de Apelaciones de Valparaíso, 22 de abril de 2016, Base Jurisprudencial del Poder Judicial (recurso de nulidad, rol Reforma Laboral No 19-2016).

Canepa con Gendarmería de Chile (2016): Corte de Apelaciones de San Miguel, 1 de abril de 2016, Base Jurisprudencial del Poder Judicial (recurso de nulidad, rol Reforma Laboral N²4-2016).

Castro con Constructora Aysén Limitada (2016): Corte de Apelaciones de Santiago, 1 de junio de 2016, Base Jurisprudencial del Poder Judicial (recurso de nulidad, rol Reforma Laboral $\left.\mathrm{N}^{\circ} 11-2016\right)$.

Celedón con Construcciones Benavente Ltda. (2016): Corte de Apelaciones de Valparaíso, 2 de febrero de 2016, Base Jurisprudencial del Poder Judicial (recurso de nulidad, rol Reforma Laboral N 5-2016).

Contreras con Agricotrans Ltda. (2016): Corte de Apelaciones de Rancagua, 22 de marzo de 2016, Base Jurisprudencial del Poder Judicial (recurso de nulidad, rol Reforma Laboral $\mathrm{N}^{\circ}$ 186-2015).

Cox con Vásquez (2016): Corte de Apelaciones de Valparaíso, 11 de octubre de 2016, Base Jurisprudencial del Poder Judicial (recurso de nulidad, rol Reforma Laboral $\mathrm{N}^{\circ}$ 406-2016).

Chan con Flex Chile Limitada (2016): Corte de Apelaciones de San Miguel, 1 de diciembre de 2016, Base Jurisprudencial del Poder Judicial (recurso de nulidad, rol Reforma Laboral $\left.N^{\circ} 397-2016\right)$.

Díaz con Arias (2016): Corte de Apelaciones de Rancagua, 18 de mayo de 2016, Base Jurisprudencial del Poder Judicial (recurso de nulidad, rol Reforma Laboral $N^{\circ}$ 27-2016).

Etura con Penta Vida Compañía de Seguros Vida S.A. (2016): Corte de Apelaciones de Santiago, 27 de septiembre de 2016, Base Jurisprudencial del Poder Judicial (recurso de nulidad, rol Reforma Laboral N 1436-2016).

Flores con Delta Ingeniería y Construcción S.A. (2016): Corte de Apelaciones de Copiapó, 9 de septiembre de 2016, Base Jurisprudencial del Poder Judicial (recurso de nulidad, rol Reforma Laboral $\mathrm{N}^{\circ}$ 80-2016).

Fuentes con Construmart S.A. (2016): Corte de Apelaciones de Santiago, 27 de agosto de 2016, Base Jurisprudencial del Poder Judicial (recurso de nulidad, rol Reforma Laboral N 1319-2016).

Gallardo con Transportes y Servicios Juan C (2016): Corte de Apelaciones de Valdivia, 17 de junio de 2016, Base Jurisprudencial del Poder Judicial (recurso de nulidad, rol Reforma Laboral N $\left.{ }^{\circ} 43-2016\right)$. 
Garrido con Díaz (2016): Corte de Apelaciones de Santiago, 5 de septiembre de 2016, Base Jurisprudencial del Poder Judicial (recurso de nulidad, rol Reforma Laboral $\left.\mathrm{N}^{\circ} 1224-2016\right)$.

González con Ingeaustral Limitada (2016): Corte de Apelaciones de Iquique, 1 de julio de 2016, Base Jurisprudencial del Poder Judicial (recurso de nulidad, rol Reforma Laboral No34-2016).

Icka con Ilustre Municipalidad (2016): Corte de Apelaciones de San Miguel, 27 de mayo de 2016, Base Jurisprudencial del Poder Judicial (recurso de nulidad, rol Reforma Laboral N 65-2016).

Maldonado con Fundición Quinta S.A. (2016): Corte de Apelaciones de Santiago, 5 de enero de 2016, Base Jurisprudencial del Poder Judicial (recurso de nulidad, rol Reforma Laboral $\left.N^{\circ} 1588-2015\right)$.

Morales con Productos Fernández S.A. (2016): Sentencia de la Corte de Apelaciones de Antofagasta, 7 de octubre de 2016, Base Jurisprudencial del Poder Judicial (recurso de nulidad, rol Reforma Laboral No 173.2016).

Orellana con Círculo Español de Santiago (2016): Corte de Apelaciones de Santiago, 13 de septiembre de 2016, Base Jurisprudencial del Poder Judicial (recurso de nulidad, rol Reforma Laboral $N^{\circ}$ 1037-2016).

Orellana con Rivera (2016): Corte de Apelaciones de Concepción, 17 de marzo de 2016, Base Jurisprudencial del Poder Judicial (recurso de nulidad, rol 134 Reforma Laboral No 17-2016).

Orellana con Termolaminados Ltda. (2016): Corte de Apelaciones de Santiago, 30 de mayo de 2016, Base Jurisprudencial del Poder Judicial (recurso de nulidad, rol Reforma Laboral N581-2016).

Páez con Exportadora e Importadora Turken S.A. (2016): Corte de Apelaciones de San Miguel, 11 de abril de 2016, Base Jurisprudencial del Poder Judicial (recurso de nulidad, rol Reforma Laboral $\mathrm{N}^{\circ}$ 93-2016).

Palma con Acoger Santiago Servicios Funerarios S.A. (2016): Corte de Apelaciones de Santiago, 26 de octubre de 2016, Base Jurisprudencial del Poder Judicial (recurso de nulidad, rol Reforma Laboral $N^{\circ}$ 1479-2016).

Paris Administradora Ltda. con Robles (2016): Corte de Apelaciones de Santiago, 20 de junio de 2016, Base Jurisprudencial del Poder Judicial (recurso de nulidad, rol Reforma Laboral N ${ }^{\circ}$ 766-2016).

Pons con Ríos (2016): Corte de Apelaciones de San Miguel, 22 de diciembre de 2016, Base Jurisprudencial del Poder Judicial (recurso de nulidad, rol Reforma Laboral $\left.\mathrm{N}^{\circ} 415-2016\right)$.

Rivera con Sociedad Comercial Chungará SR (2016): Corte de Apelaciones de Iquique, 8 de junio de 2016, Base Jurisprudencial del Poder Judicial (recurso de nulidad, rol Reforma Laboral No 31-2016).

Rollino con Constructora Ecisa Chile S.A. (2016): Corte de Apelaciones de Santiago, 17 de marzo de 2016, Base Jurisprudencial del Poder Judicial (recurso de nulidad, rol Reforma Laboral $\left.N^{\circ} 17-2016\right)$. 
Rojas con Transporte y Maquinaria B y B (2016): Corte de Apelaciones de La Serena, 9 de junio de 2016, Base Jurisprudencial del Poder Judicial (recurso de nulidad, rol Reforma Laboral N²2-2016).

Rugel con Bastias (2016): Corte de Apelaciones de Santiago, 9 de mayo de 2016, Base Jurisprudencial del Poder Judicial (recurso de nulidad, rol Reforma Laboral $\mathrm{N}^{\circ}$ 461-2016).

SCM Lumina Copper con Inspección Provincial del Trabajo de Copiapó (2016): Corte de Apelaciones de Copiapó, 21 de julio de 2016, Base Jurisprudencial del Poder Judicial (recurso de nulidad, rol Reforma Laboral N 53-2016).

Siefeld con Well and Food (2016): Corte de Apelaciones de Valparaíso, 5 de enero de 2016, Base Jurisprudencial del Poder Judicial (recurso de nulidad, rol Reforma Laboral N $\left.{ }^{\circ} 483-2015\right)$.

Seil E \& C CO Ltd. con Donoso (2016): Corte de Apelaciones de Antofagasta, 28 de enero de 2016, Base Jurisprudencial del Poder Judicial (recurso de nulidad, rol Reforma Laboral $\left.\mathrm{N}^{\circ} 188-2015\right)$.

Silva con Santibáñez (2016): Corte de Apelaciones de Valparaíso, 29 de enero de 2016, Base Jurisprudencial del Poder Judicial (recurso de nulidad, rol Reforma Laboral N 481-2015).

Sindicato de Tripulantes de CPT Remolcadores S.A. con CPT Remolcadores S.A. (2016): Corte de Apelaciones de Concepción, 22 de agosto de 2016, Base Jurisprudencial del Poder Judicial (recurso de nulidad, rol Reforma Laboral N²00-2016).

Sociedad Educacional INMA Ltda. con Vega (2016): Corte de Apelaciones de Antofagasta, 28 de junio de 2016, Base Jurisprudencial del Poder Judicial (recurso de nulidad, rol Reforma Laboral $\mathrm{N}^{\circ}$ 91-2016).

Toro con Rivera (2016): Corte de Apelaciones de Valparaíso, 11 de marzo de 2016, Base Jurisprudencial del Poder Judicial (recurso de nulidad, rol Reforma Laboral $\left.\mathrm{N}^{\circ} 47-2015\right)$.

Troncoso con Proservice Ltda. (2016): Corte de Apelaciones de Santiago, 13 de junio de 2016, Base Jurisprudencial del Poder Judicial (recurso de nulidad, rol Reforma Laboral $\mathrm{N}^{\circ}$ 626-2016).

Vega con Ingeniería y Desarrollo Isistem S.P.A. (2016): Corte de Apelaciones de La Serena, 1 de julio de 2016, Base Jurisprudencial del Poder Judicial (recurso de nulidad, rol Reforma Laboral $N^{\circ}$ 69-2016).

Corte Suprema de Chile

Artigas con Corporación de Asistencia Judicial (2014): Corte Suprema, 14 de abril de 2014, Base Jurisprudencial del Poder Judicial (recurso de unificación de jurisprudencia, rol No 8070-2013).

Prosegur Chile S.A. con Llanos y otros (2014): Corte Suprema, 10 de marzo de 2014, Base Jurisprudencial del Poder Judicial (recurso de queja, rol $\mathrm{N}^{\circ} 12.253$ 2013). 


\section{Tribunal Constitucional de Chile}

Sentencia rol N 1384-2009-INA, 14 de mayo de 2009.

\section{Normas citadas}

Código de Procedimiento Civil, de 1902: art. 313.

Constitución Política de la República, de 1980: art. 19

Código del Trabajo chileno, de 1994: arts. 425, 430, 432, 436, 437, 446, 451, 453, 456, 457, 459, 477, 479, 491, 500, 501, 503, 504, 512.

Ley $\mathrm{N}^{\circ} 20.087$, sustituye el procedimiento laboral contemplado en el libro $\mathrm{v}$ del Código del Trabajo, publicada en el Diario Oficial, Santiago, 3 de enero de 2006.

Ley $\mathrm{N}^{\circ} 20.260$, modifica el libro v del Código del Trabajo y la ley $\mathrm{N}^{\circ} 20.087$, que establece un nuevo procedimiento laboral, publicada en el Diario Oficial, Santiago, 29 de marzo de 2008. 